\title{
Changes in average and extreme precipitation in two regional climate model experiments
}

\author{
By JOUNI RÄISÄNEN* and RUNE JOELSSON, Rossby Centre, Swedish Meteorological and \\ Hydrological Institute, S-60176 Norrköping, Sweden
}

(Manuscript received 1 November 2000; in final form 3 May 2001)

\begin{abstract}
Two regional climate model experiments for northern and central Europe are studied focussing on greenhouse gas-induced changes in heavy precipitation. The average yearly maximum oneday precipitation $P_{\max }$ shows a general increase in the whole model domain in both experiments, although the mean precipitation $P_{\text {mean }}$ decreases in the southern part of the area, especially in one of the experiments. The average yearly maximum six-hour precipitation increases even more than the one-day $P_{\max }$, suggesting a decrease in the timescale of heavy precipitation. The contrast between the $P_{\text {mean }}$ and $P_{\max }$ changes in the southern part of the domain and the lack of such a contrast further north are affected by changes in wet-day frequency that stem, at least in part, from changes in atmospheric circulation. However, the yearly extremes of precipitation exhibit a larger percentage increase than the average wet-day precipitation. The signal-to-noise aspects of the model results are also studied in some detail. The $44 \mathrm{~km}$ grid-box-scale changes in $P_{\max }$ are very heavily affected by inter-annual variability, with an estimated standard error of about $20 \%$ for the 10 -year mean changes. However, the noise in $P_{\max }$ decreases sharply toward larger horizontal scales, and large-area mean changes in $P_{\max }$ can be estimated with similar accuracy to those in $P_{\text {mean }}$. Although a horizontal averaging of model results smooths out the small-scale details in the true climate change signal as well, this disadvantage is, in the case of $P_{\max }$ changes, much smaller than the advantage of reduced noise.
\end{abstract}

\section{Introduction}

Potential increases in heavy precipitation allowed by a larger moisture content in a warmer atmosphere are an important (e.g. considering the risk of flooding) and relatively widely studied aspect of greenhouse gas-induced climate changes. There is some evidence of such increases in the observational record for the last 50-100 years, although the increase has not been globally uniform, due probably to the fact that many regional trends are still dominated by the natural variability of climate (Easterling et al., 2000). Model experiments that simulate the response of climate to larger increases in greenhouse gases, such as a doubling of $\mathrm{CO}_{2}$,

\footnotetext{
* Corresponding author e-mail: jouni.raisanen@smhi.se
}

generally point toward a continued upward trend in precipitation extremes in the future.

A general greenhouse-gas induced increase in heavy precipitation is a very prevalent model result (e.g. Noda and Tokioka, 1989; Gordon et al., 1992; Whetton et al., 1993; Gregory and Mitchell, 1995; Hennessy et al., 1997; Jones et al., 1997; Zwiers and Kharin, 1998; Meehl et al., 2000). Despite some variation amongst different studies (Parey (1994) found no systematic change in heavy precipitation statistics in the LMD model), this increase may in fact be a more "certain" and globally uniform consequence of an enhanced greenhouse effect than an increasing mean precipitation. Support for this idea comes from a range of studies with several different approaches to characterise the precipitation statistics. For example, in their CSIRO4 general circulation

Tellus 53A (2001), 5 
model (GCM), Gordon et al. (1992) found a more widespread increase in average rain intensity (averaged over the days with at least $0.2 \mathrm{~mm}$ of precipitation) than in the mean precipitation. Using the UKHI and CSIRO9 GCMs, Hennessy et al. (1997) reported a general decrease in the total number of wet days in low and mid-latitudes and an increase in high latitudes, but an increasing number of days with heavy precipitation in almost all latitude zones. In the study by Zwiers and Kharin (1998) of the response of the CCC GCM2 to a doubling of $\mathrm{CO}_{2}$, the 20-year return value of daily precipitation was found to increase almost everywhere, in contrast with the mean precipitation which also showed wide areas of decrease. The globally averaged 20-year return value increased by $11 \%$ but the global mean precipitation by only $4 \%$. Nevertheless, as in the case with the mean precipitation, the changes in regional heavy precipitation statistics can not be described by a single globally averaged number.

This paper contributes to the research on greenhouse gas-induced changes in heavy precipitation by analysing two $44 \mathrm{~km}$ resolution experiments made with the Rossby Centre regional atmospheric climate model (RCA) for northern and central Europe. The two experiments were driven by boundary forcing data from two GCMs, HadCM2 (Johns et al., 1997; Mitchell and Johns, 1997) and ECHAM4/OPYC3 (Roeckner et al., 1996, 1999; Oberhuber, 1993). Our model area has received little detailed attention in earlier studies on the subject, although some results were presented by Gregory and Mitchell (1995) mainly for central Europe and by Jones et al. (1997) in terms of European mean precipitation class frequencies. Furthermore, most studies on greenhouse gas-induced changes in heavy precipitation have thus far been based on GCM rather than regional climate model (RCM) experiments (but see Jones et al. (1997) for an exception). At the very least, the higher resolution of RCMs has the advantage that it allows the magnitude of intense precipitation to be captured more realistically in the control simulations (Christensen et al., 1998).

The main parameter used in this study is the average yearly maximum one-day precipitation $P_{\max }$, a compromise between the need for information on the real, practically important extremes and the need for meaningful statistics from short experiments. Some results are also given for the average yearly maximum six-hour precipitation $P_{\max 6}$. Unlike some other useful statistics related to heavy precipitation, such as the frequency of precipitation events exceeding a given threshold, the changes in $P_{\max }$ and $P_{\max 6}$ are directly comparable with those of the mean precipitation $P_{\text {mean }}$. For impact researchers, who require estimates of precipitation extremes in a future climate, it is often tempting to assume that the extremes will change with the same relative percentage amount as the mean precipitation, either because a direct evaluation of the extremes from daily model data is considered a difficult task or because such daily data are unavailable. We will study here the similarity between the $P_{\text {mean }}$ and $P_{\max }$ changes in the RCA experiments and try to find some explanations for the differences.

Some specific attention is paid to the signal-tonoise issue. The experiments studied here are only 10 years long, which renders their results potentially sensitive to internal variability, particularly concerning the changes in extremes. One symptom of this is the very noisy geographical pattern of the simulated $P_{\max }$ changes, which gives little indication of a reproducible climate change signal. It is shown that the impact of internal variability can be reduced substantially by smoothing the results horizontally. While such smoothening also removes small-scale details in the true climate change signal, this disadvantage does not outweigh the reduced noise. It is also found that a majority of the differences in $P_{\max }$ and $P_{\text {mean }}$ change between the two experiments are likely to arise from internal variability, rather than from differences between the two GCMs providing the boundary data for these regional experiments.

Section 2 below describes the RCM used and the two climate change experiments made with different GCM boundary data. $P_{\max }$ and $P_{\text {mean }}$ in the control runs are compared with observational estimates in Section 3. The simulated greenhouse gas-induced changes in $P_{\text {mean }}, P_{\max }$ and $P_{\max 6}$, and issues related to their physical interpretation, are discussed in Section 4, while the signal-to-noise issue is studied in Section 5. The main findings are summarised in Section 6.

\section{The experiments}

The two experiments were made with the Rossby Centre regional atmospheric climate 
model (RCA) for northern and central Europe, using boundary forcing data from two atmosphere-ocean GCMs, HadCM2 (Johns et al., 1997; Mitchell and Johns, 1997) and ECHAM4/OPYC3 (Roeckner et al., 1996; 1999; Oberhuber, 1993). RCA was run in a rotated latitude-longitude grid at $44 \mathrm{~km}$ horizontal resolution and with 19 hybrid levels between the surface and $10 \mathrm{hPa}$. It was forced by the driving GCMs from its lateral boundaries (eight-point relaxation zones were used) and from below, by sea surface temperatures (SSTs) and deep soil temperatures.

RCA was developed from the version 2.5 of the limited area weather forecast model HIRLAM (Källén, 1996; Eerola et al., 1997), which is used in several European countries. Changes from HIRLAM include several updates to the soil and snow scheme and the inclusion of explicit modules for inland lakes (Ljungemyr et al., 1996; Omstedt, 1999 ) and the Baltic Sea (Omstedt and Nyberg, 1996). These changes are described in some detail by Rummukainen et al. (2001). For the experiments discussed here, the original HIRLAM radiation scheme was also modified (Räisänen et al., 2000). Unlike the original scheme, the new version allows for increasing $\mathrm{CO}_{2}$ in climate change simulations. This has nearly eliminated the tendency of RCA to simulate smaller warming in climate change experiments than the driving GCMs, which was present in the earlier $88 \mathrm{~km}$ experiments discussed by Räisänen et al. (2001).

The original HIRLAM cloud and precipitation parameterisations are retained. Cloud water is a prognostic variable. It is produced as a result of either stratiform condensation induced by explicitly resolved ascent, or of deep convection parameterised with a Kuo-type scheme (Kuo, 1965; 1974). The cloud microphysics, including the generation and possible re-evaporation of precipitation, are parameterised according to Sundqvist et al. (1989) and Sundqvist (1993).

Two GCM time slices of slightly longer than 10 years were used for both of the regional climate change experiments, denoted as $\mathrm{RH}$ ( RCA/HadCM2) and RE (RCA/ECHAM4). One of the time slices acted as a control period and the other as a scenario period representing a future with higher greenhouse gas concentrations. No sulphate aerosol forcing was included in either RCA or the driving GCMs. The present analysis uses the last full 10 years of the four RCA runs.
The first few RCA simulated months are ignored to avoid spin-up.

The boundary data for $\mathrm{RH}$ are from partial reruns* of two long HadCM2 simulations; that is, a control run and a transient greenhouse run, in which gradually increasing $\mathrm{CO}_{2}$ represents the change in greenhouse gas forcing from the preindustrial era. The period used from the HadCM2 transient run is 2039-2049. The RE boundary forcing data are from a present-day (nominally 1980s) and a future (2070s) time slice from a transient ECHAM4/OPYC3 greenhouse run (as with $\mathrm{RH}$, the first of these was a rerun). $\mathrm{RH}$ and $\mathrm{RE}$ therefore differ in terms of the periods, and this is also the case with the greenhouse gasinduced radiative forcing in the driving GCMs. The forcing in HadCM2, resulting from a $150 \%$ increase in $\mathrm{CO}_{2}$, is about $20 \%$ larger than that in ECHAM4/OPYC3, in which increases are prescribed separately for $\mathrm{CO}_{2}, \mathrm{CH}_{4}, \mathrm{~N}_{2} \mathrm{O}$ and several CFCs (Fig. 0.3 of Machenhauer et al., 1998). Nevertheless, the global mean surface air warming between the two time slices is almost the same $(2.6 \mathrm{~K})$ in both of the two GCMs. In this sense, the RH and RE experiments do form a quantitatively comparable pair.

Regarding the changes in time mean temperature and precipitation, the conclusions of Räisänen et al. (2001) hold even for the present experiments. Even on the $44 \mathrm{~km}$ grid box scale, the differences between RCA and the driving GCM are typically smaller than the differences between the two GCM experiments. Thus, these aspects of the time mean climate change in RCA are strongly controlled by the driving GCMs. The lack of daily precipitation data for the GCMs prevents us from determining whether this is also true for the changes in extreme precipitation.

\section{Control run precipitation}

The 10-year average $P_{\text {mean }}$ and $P_{\max }$ distributions in the two RCA control runs are mapped in

* Reruns were needed to obtain a data set detailed enough for driving RCMs. Because of the use of a different computer and a chaotic amplification of the associated (initially) bit-level differences, these reruns are not identical to the same decades in the original, longer HadCM2 simulations. 
Fig. 1, together with the observed $P_{\text {mean }}$ according to the CRU climatology for 1961-1990 (Hulme et al., 1995). The eight-point boundary zones are excluded from all figures and analysis in this paper.

Many of the geographical features of the observed $P_{\text {mean }}$ are reproduced in the simulations. The land area spatial correlation with CRU is 0.79 for $\mathrm{RH}$ and 0.65 for RE, and the bias relative to the CRU land area mean $+16 \%$ and $+10 \%$, respectively. As the CRU data have not been corrected for precipitation under-catch in the observations, the positive area mean biases are at least partly artificial. However, the modest area mean bias in RE results from a compensation between a clear negative bias in the southernmost part of the domain and substantial positive biases further north in central Europe and in Scandinavia. The biases also vary seasonally and are, in much of the area and both experiments, the most strongly positive in winter and in spring. These results are largely similar to those reported by Rummukainen et al. (2001) for an earlier $88 \mathrm{~km}$ version of the same model, although the $P_{\text {mean }}$ in the present $44 \mathrm{~km}$ simulations is slightly larger in most of the area.

The 10-year mean $P_{\max }$ in the RCA control simulations is in most low-altitude areas around $30 \mathrm{~mm}$ day $^{-1}$. Larger values occur near the Alps and in western Norway, although the orographic contrasts are somewhat less pronounced than is the case with $P_{\text {mean }}$. Because of more limited data availability, $P_{\max }$ is more difficult to compare with observations than $P_{\text {mean }}$. Table 1 gives results for the 12 Swedish locations mapped in Fig. 2, comparing station observations for 1961-1990 with the closest RCA grid boxes. The agreement is reasonable. On the average, for this set of stations, $P_{\max }$ is underestimated by just $10 \%$ in $\mathrm{RH}$ and overestimated by just $9 \%$ in RE. According to a standard $t$-test (see Appendix A for the definition of this test and a discussion of its suitability for evaluating the significance of $P_{\max }$ differences), the differences between the simulated and observed $P_{\max }$ are statistically insignificant in most cases. As illustrated by the figures in the last row of the table, the inter-annual variability of $P_{\max }$ is also reasonably similar between the simulations and the station observations.

Given that the RCA grid boxes have an area of about $2000 \mathrm{~km}^{2}$, it could be argued that the model should underestimate the $P_{\max }$ on the local scale captured by the station observations. On the other hand, the real $P_{\max }$ is likely to be somewhat larger than that observed, because gauge measurements tend to undercatch precipitation. However, we speculate that this observational bias may be smaller for $P_{\max }$ than for $P_{\text {mean }}$, since the largest daily precipitation events in Sweden usually occur during the warmer part of the year when precipitation is liquid and the measurements are therefore less affected by aerodynamic effects. In any case, be it fortuitous or not, the agreement between the model and these Swedish station observations is better for $P_{\max }$ than for $P_{\text {mean }}$. The latter is overestimated, in particular in RE, seemingly due to an excessive number of light and moderate precipitation events.

\section{Changes in average and extreme precipitation and some related quantities}

\subsection{Geographical distributions}

The scenario minus control run precipitation changes $\Delta P_{\text {mean }}$ and $\Delta P_{\max }$ are shown in Fig. 3, both in per cent of the control run means. $P_{\text {mean }}$ increases in most of northern Europe and northern North Atlantic in both experiments, locally by up to $30 \%$, but with somewhat different geographical patterns in RH and RE. In central Europe, slight decreases in $P_{\text {mean }}$ dominate in RE, although the decrease is statistically significant at the $95 \%$ level in only a small part of the area. In RH, increases in $P_{\text {mean }}$ extend further south than in RE. Near the southern edge of the map, some areas of significant decrease occur even in $\mathrm{RH}$, but there are also strong local increases to the south of the Alps and in the south-eastern corner of the domain.

$P_{\max }$ increases in most of the domain in both RH and RE, including much of those areas where $P_{\text {mean }}$ decreases. However, the geographical patterns of $\Delta P_{\max }$ are extremely noisy, and the areas where $\Delta P_{\max }$ is statistically significant are much more fragmented than is the case with $\Delta P_{\text {mean }}$. This might suggest that the RCA experiments are too short to gain useful information on the $P_{\max }$ changes. However, as illustrated in Fig. 4, this is not true.

Fig. 4a shows the RE control and scenario run time series of $P_{\max }$ in a single grid box (identified in the lower right panel of Fig. 3) and Figs. 4b-c 


\section{Pmean}
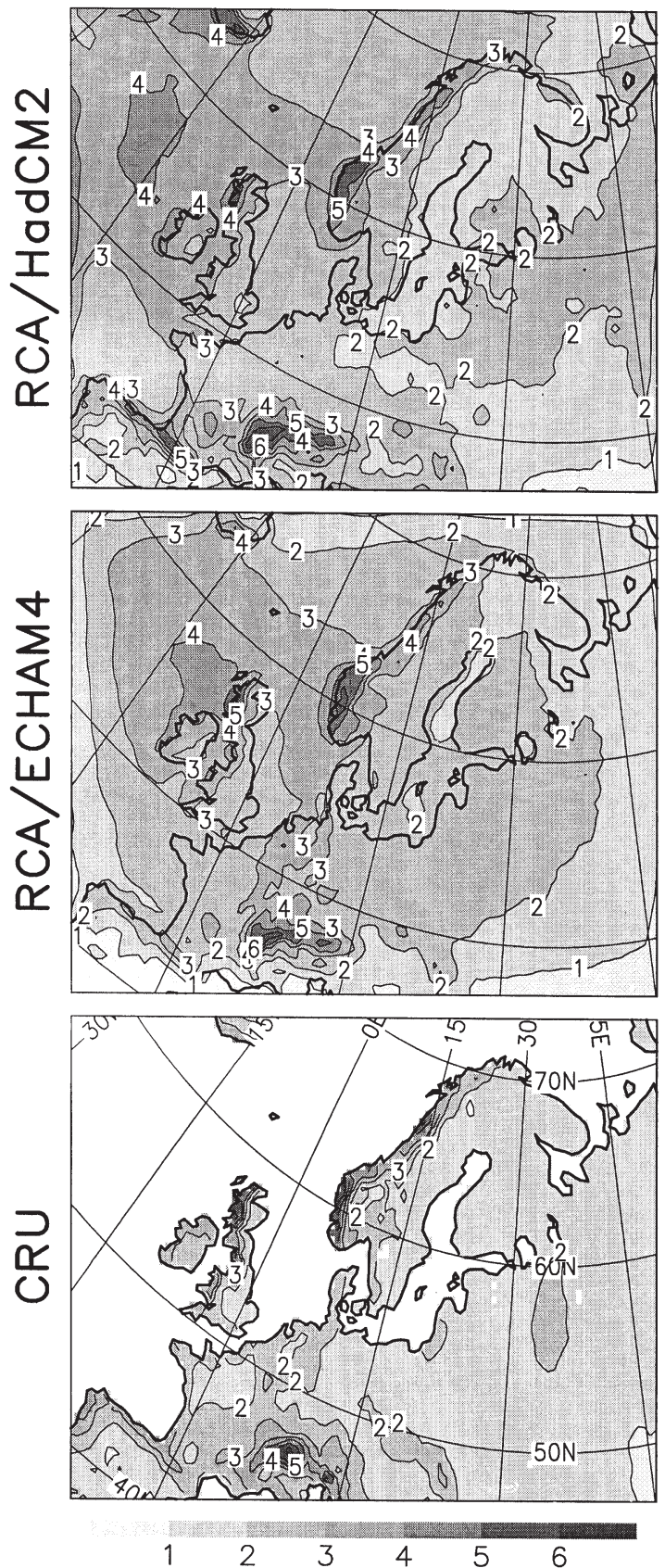

\section{$P \max$}
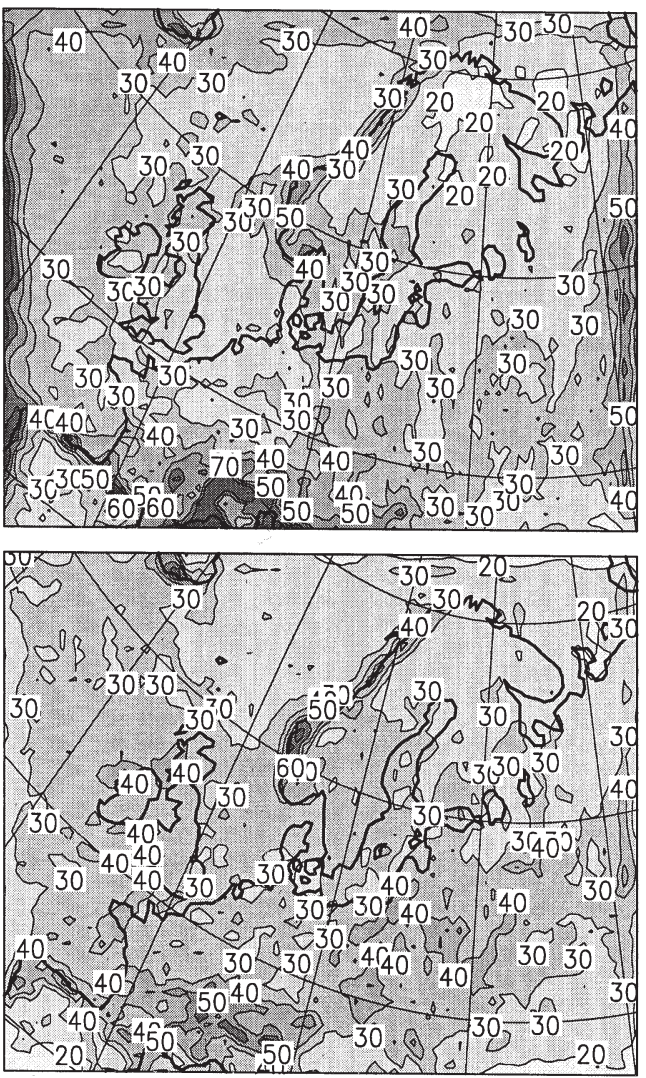

$\begin{array}{llllll}20 & 30 & 40 & 50 & 60 & 70\end{array}$

Fig. 1. Left: annual mean precipitation $\left(\mathrm{mm} \mathrm{day}^{-1}\right)$ in the two RCA control runs and according to the CRU climatology for 1961-1990. Right: average yearly maximum one-day precipitation in the RCA control runs. 
Table 1. Annual mean precipitation $\left(P_{\text {mean }}\right)$ and mean yearly maximum one-day precipitation $\left(P_{\max }\right)$ at 12 Swedish sites according to station observations (1961-1990) and in the RH and RE control simulations. Simulated values that at the 95\% significance level are different from those observed are marked in bold (positive differences) or by underlining (negative differences). The inter-annual standard deviation (SD) in the last row is the square root of the 12-station mean of the inter-annual variance

\begin{tabular}{|c|c|c|c|c|c|c|c|}
\hline \multirow{2}{*}{\multicolumn{2}{|c|}{ Station }} & \multicolumn{3}{|c|}{$P_{\text {mean }}\left(\mathrm{mm} \mathrm{day}^{-1}\right)$} & \multicolumn{3}{|c|}{$P_{\max }\left(\mathrm{mm} \mathrm{day}^{-1}\right)$} \\
\hline & & Obs & RH & $\mathrm{RE}$ & Obs & RH & $\mathrm{RE}$ \\
\hline 1 & Växjö & 1.79 & 2.27 & 2.81 & 30.1 & 36.6 & 36.6 \\
\hline 2 & Säve & 2.12 & 2.25 & 2.79 & 30.7 & 34.6 & 38.7 \\
\hline 3 & Stockholm & 1.48 & 1.86 & 2.30 & 30.2 & 31.2 & 33.5 \\
\hline 4 & Karlstad & 1.74 & 2.11 & 2.70 & 32.9 & 29.8 & 33.1 \\
\hline 5 & Uppsala & 1.49 & 1.86 & 2.30 & 29.4 & 29.5 & 35.0 \\
\hline 6 & Falun & 1.69 & 2.02 & 2.60 & 34.0 & 29.9 & 35.5 \\
\hline 7 & Härnösand & 1.93 & 1.87 & 2.52 & 41.5 & 32.2 & 37.5 \\
\hline 8 & Östersund & 1.33 & 1.90 & 2.56 & 29.4 & $\overline{22.3}$ & 40.5 \\
\hline 9 & Stensele & 1.45 & 1.92 & 2.43 & 30.0 & $\overline{23.4}$ & 29.4 \\
\hline 10 & Haparanda & 1.53 & 1.73 & 2.11 & 26.0 & $\overline{20.3}$ & 29.1 \\
\hline 11 & Jokkmokk & 1.40 & 1.80 & 2.45 & 29.6 & $\overline{22.2}$ & 26.4 \\
\hline \multirow[t]{2}{*}{12} & Katterjákk & 2.46 & 3.78 & 3.47 & 36.9 & $\overline{29.2}$ & 39.3 \\
\hline & $\begin{array}{l}\text { Average } \\
\text { (Inter-annual SD) }\end{array}$ & $\begin{array}{l}1.70 \\
(0.27)\end{array}$ & $\begin{array}{c}\mathbf{2 . 1 1} \\
(0.29)\end{array}$ & $\begin{array}{c}\mathbf{2 . 5 9} \\
(0.30)\end{array}$ & $\begin{array}{c}31.7 \\
(10.4)\end{array}$ & $\frac{28.4}{(8.5)}$ & $\begin{array}{c}34.6 \\
(12.1)\end{array}$ \\
\hline
\end{tabular}

area means of $P_{\max }$ over the surrounding $7 \times 7$ and $17 \times 17$ grid boxes $(310 \times 310 \mathrm{~km}$ and $750 \times 750 \mathrm{~km}$, respectively). Finally, the area means over all land grid boxes in the map domain of Fig. 3 are given in Fig. $4 \mathrm{~d}$. In the single grid box, the control and the scenario run time series are both characterised by very strong inter-annual variability and they have, incidentally, almost identical 10-year means. However, the interannual variability decreases dramatically with an increasing averaging domain, which renders the difference between the two runs to be much more discernible. In the whole land area, the lowest yearly scenario run area mean of $P_{\max }$ exceeds the highest control run area mean, and the $t$-value of 8.0 (eq. (A1)) exceeds the threshold for $95 \%$ significance (2.101) by almost a factor of four. Thus, despite the strong small-scale noise, the experiments do provide statistically meaningful information on $P_{\max }$ changes on larger spatial scales. The noise associated with inter-annual variability and its implications for the interpretation of the RCA experiments will be discussed further in Section 5.

\subsection{Area mean changes}

Annual land area mean changes in $P_{\text {mean }}$ and $P_{\max }$ along with some other precipitation para- meters are given in Table 2. In addition to the whole land area, results are shown separately for the southern $(\mathrm{S} 55=$ land south of the latitude $55^{\circ} \mathrm{N}$, which is indicated by the dashed line in Fig. 3) and northern $\left(\mathrm{N} 55=\right.$ land north of $\left.55^{\circ} \mathrm{N}\right)$ parts of the domain. As expected from Fig. 3, there is a contrast between the two sub-regions in $\Delta P_{\text {mean }}$, between substantial increases in N55 and smaller, statistically insignificant changes (an increase in $\mathrm{RH}$ and a decrease in RE) in S55. By contrast, $P_{\max }$ increases significantly in both $\mathrm{S} 55$ and N55 in both experiments, in the latter area approximately as much as $P_{\text {mean }}$.

The largest one-day precipitation totals seldom result from temporally uniform precipitation during the whole 24-hour period. Therefore, we also calculated $P_{\max 6}$, the largest yearly six-hour precipitation (third row of Table 2). $P_{\max 6}$ increases even more than $P_{\max }$, in the whole land area mean by about $20 \%$ rather than $15 \%$. The modified $t$-test described in the end of Appendix A indicates this difference to be highly statistically significant. Thus, the timescale of heavy precipitation appears to decrease. This is qualitatively consistent with a difference between the $\mathrm{RH}$ and $\mathrm{RE}$ control simulations. The simulated temperatures are generally higher in RE than in $\mathrm{RH}$ (on 


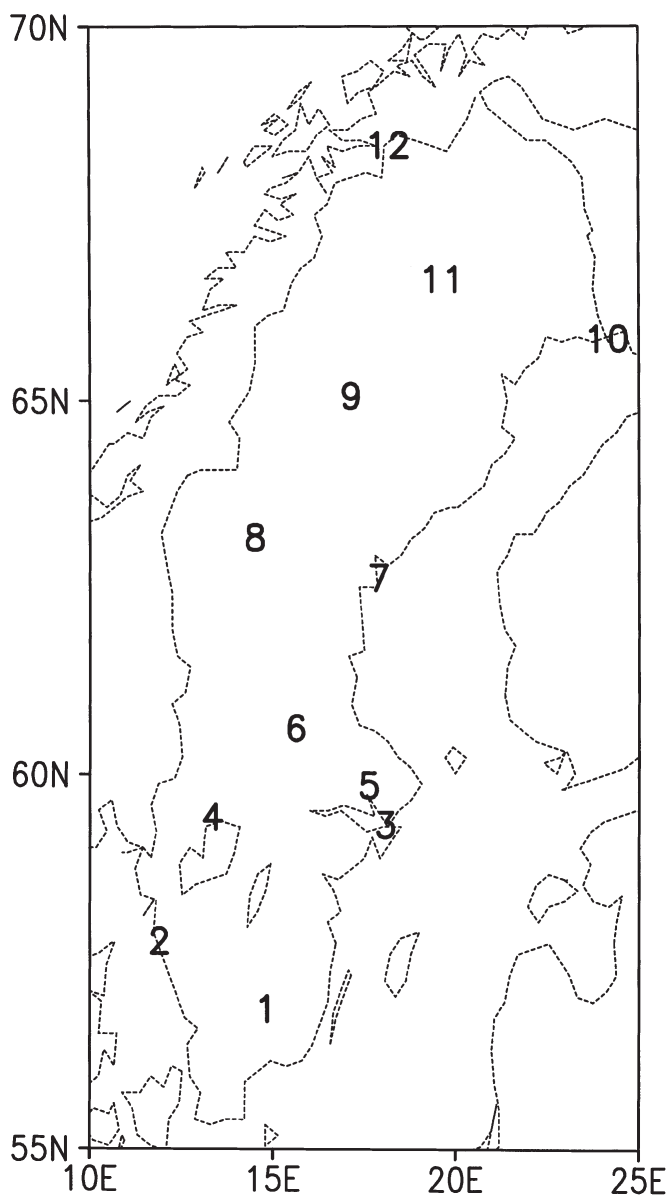

Fig. 2. The 12 Swedish stations used in Table 1 .

the average, by $2^{\circ} \mathrm{C}$ in the lower troposphere), and so is the ratio between the control run area means of $P_{\max 6}$ and $P_{\max }$ (compare rows 2 and 3 in Table 2). Nevertheless, the robustness of this result should be checked with other models.

Most of the extreme six-hour and one-day precipitation events in RCA are produced by stratiform condensation associated with ascent on the $44 \mathrm{~km}$ grid scale, rather than by deep convection. This feature may or may not be realistic. Comparison with observations is problematic both due to a lack of suitable digitised data sets and because the borderline between convective and stratiform precipitation is in reality ill-defined. Statistics for the simulated six-hour maxima of the stratiform and convective precipitation components are given on rows 4 and 5 in Table 2 . The scenario minus control run changes in the extremes of the dominating stratiform component are very similar to the changes in the extremes of total precipitation. The same is true even on the one-day timescale (not shown).

It is natural to think that a decrease in the timescale of heavy precipitation might be accompanied by a decrease in its horizontal scale. To study this possibility, the RCA simulated precipitation totals were replaced in each grid box by averages representing a typical GCM resolution $(7 \times 7$ grid boxes $\approx 310 \times 310 \mathrm{~km})$. The average $P_{\max }$ and $P_{\max 6}$ values for these series were then calculated in the usual manner. The results are, however, ambiguous (rows 6 and 7 in Table 2). The $310 \mathrm{~km}$ time series do yield slightly smaller per cent increases in $P_{\max }$ and especially $P_{\max 6}$ than the grid-box-scale time series in RE, but there is little difference between the two scales in $\mathrm{RH}$.

Different per cent changes in $P_{\max }$ and $P_{\text {mean }}$ might, in principle, be explained by a change in wet-day frequency alone, with no change other than a constant relative shift in the probability distribution of wet-day precipitation. Alternatively, such differences might result from a redistribution of daily precipitation totals amongst a constant number of wet days (e.g. largest per cent increases in the upper end of the distribution). To study which of these alternatives is closer to the truth in the RCA experiments, the number of wet days with over $1 \mathrm{~mm}$ of precipitation $\left(N_{\text {wet }}\right)$ and the average precipitation per wet day (precipitation intensity $P_{\text {wet }}$ ) were computed. Days with light precipitation of between 0.1 and $1 \mathrm{~mm}$ were excluded since, albeit their number in RCA is large (about 120 per year when averaged over the whole land area), they only contribute $6-7 \%$ to the total area mean precipitation.

$N_{\text {wet }}$ (row 8 in Table 2) increases by about $5 \%$ in $\mathrm{N} 55$ but it decreases in $\mathrm{S} 55$, by $1.7 \%$ in $\mathrm{RH}$ and by as much as $12.5 \%$ in RE. Consequently, the changes in $P_{\text {wet }}$ (row 9) are more similar between the two sub-regions, and in S55 between the two experiments, than are the changes in $P_{\text {mean }} . P_{\text {wet }}$ increases in both sub-regions in both RH and RE, but not as much as $P_{\max }$ does (the difference $\Delta P_{\max }-\Delta P_{\text {wet }}$ in the whole land area is statistically significant in both experiments). These results indicate that both the changes in wet-day frequency and the redistribution of precipitation 


\section{$\mathrm{RCA} / \mathrm{HadCM} 2$}
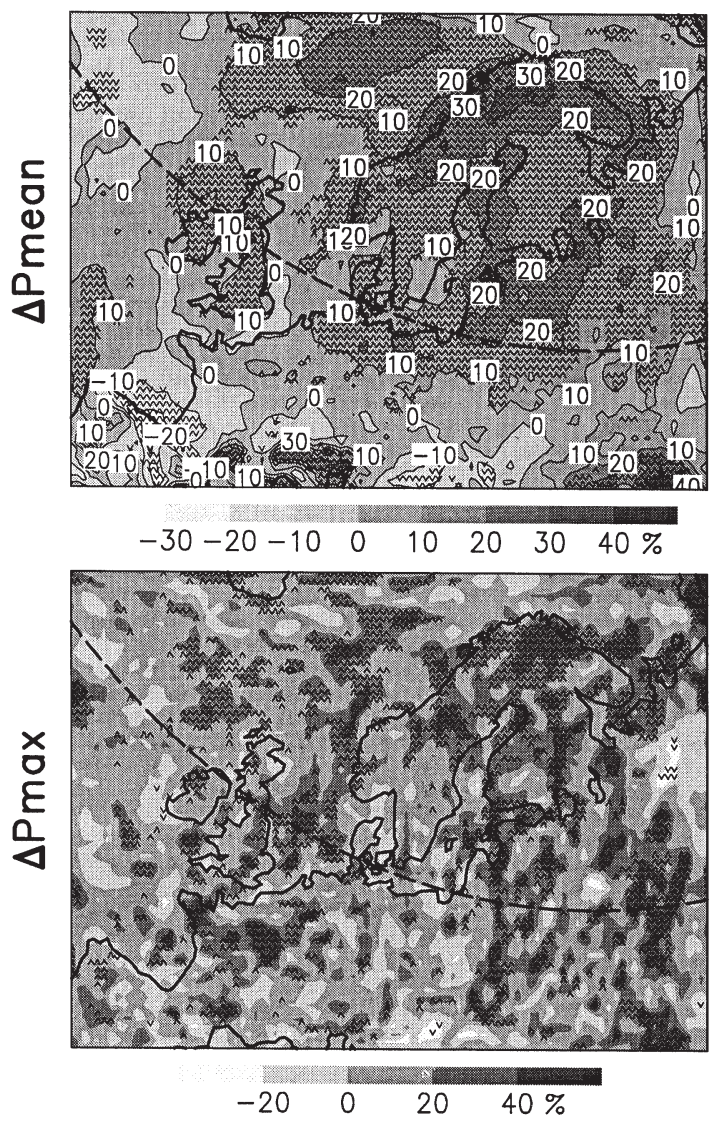

RCA/ECHAM4

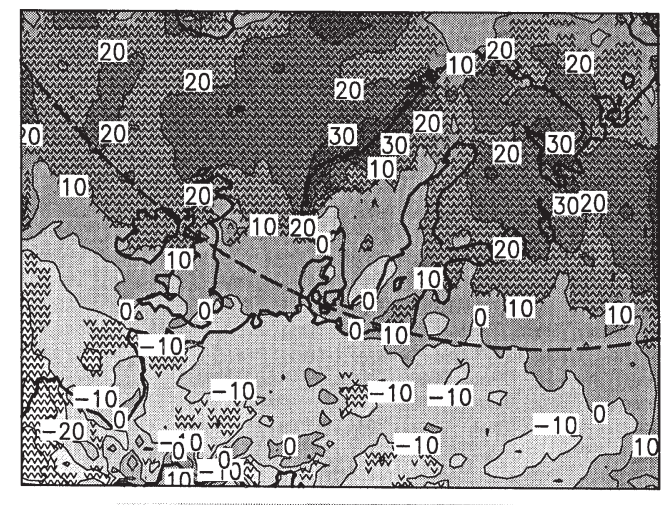

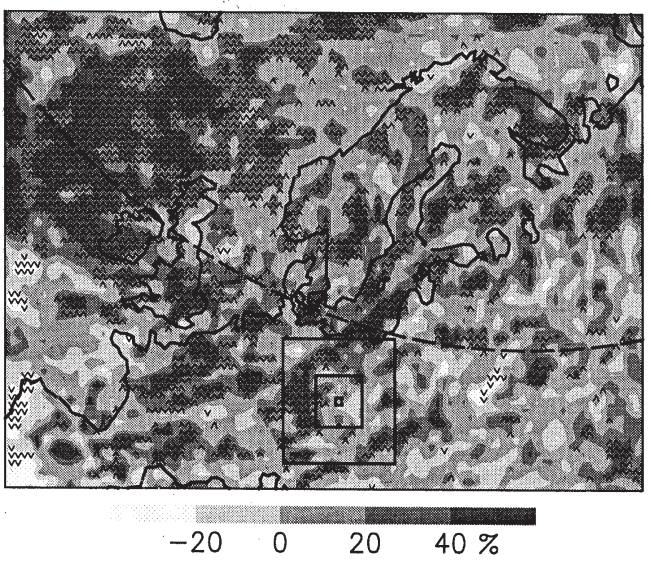

Fig. 3. Changes in annual mean precipitation (top; contours and shading at every $10 \%$ ) and the average yearly maximum one-day precipitation (bottom; shading at every 20\%) in the two RCA experiments. Changes that are statistically significant at the $95 \%$ level are indicated with small arrowheads. The thick dashed line shows the $55^{\circ} \mathrm{N}$ latitude. The three squares in the lower part of the bottom right panel are used in Fig. 4.

totals amongst the wet days contribute to the differences between $\Delta P_{\max }$ and $\Delta P_{\text {mean }}$.

Finally, for comparison with the changes in the average yearly precipitation extremes on rows 2 and 3 of Table 2, the changes in the absolute maximum one-day and six-hour precipitation for the whole ten-year period are given on rows 10 and 11 . The increases in the absolute extremes are in a majority of cases slightly larger than those in the average annual extremes, but the difference is not systematic.

The seasonal distribution of the simulated $P_{\text {mean }}$, $P_{\text {wet }}$ and $P_{\max }$ changes in the two sub-regions is shown in Fig. 5. Here, $P_{\max }$ is defined as the 10-year mean of the largest daily precipitation within a three-month season, which represents a somewhat less extreme event (frequency 1/90) than the annual $P_{\max }(1 / 360)$.

In N55, $P_{\text {mean }}$ increases in all four seasons $(\mathrm{DJF}=$ December-February; $\quad \mathrm{MAM}=$ March May; JJA = June-August; SON = SeptemberNovember), although the increase in JJA is much smaller in $\mathrm{RE}$ than in $\mathrm{RH}$. In $\mathrm{S} 55, P_{\text {mean }}$ only increases significantly in RH in MAM. The changes in the other seasons are within the $95 \%$ probability interval of internal variability, excluding a large decrease $(23 \%)$ in RE in JJA that is explained by a $34 \%$ decrease in the number of 
a) One grid box

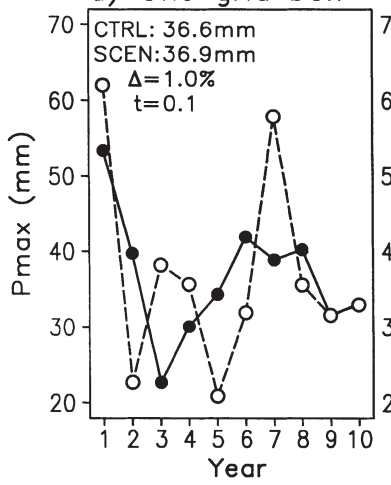

b) $7 \times 7$ boxes

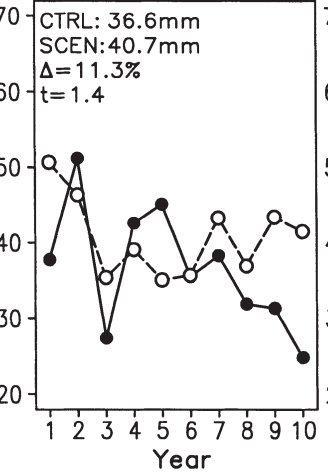

c) $17 \times 17$ boxes

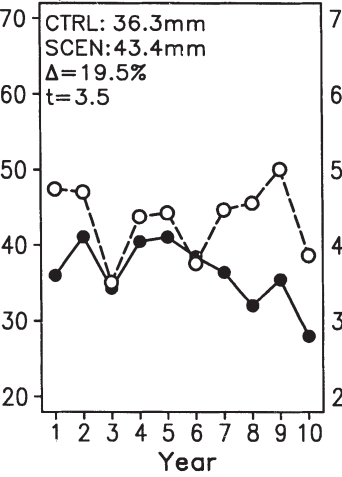

d) Land mean

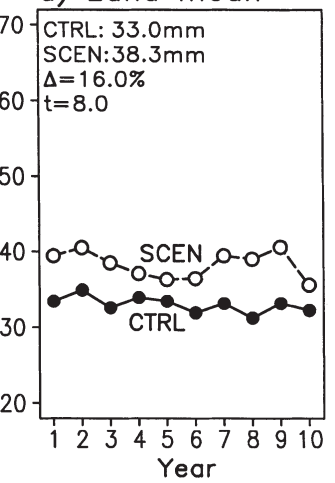

Fig. 4. Yearly values of $P_{\max }$ in the RE control run (solid lines) and scenario run (dashed lines). (a) shows the time series in the grid box indicated by the innermost square in the lower right panel of Fig. 3, (b) and (c) the area means over the surrounding $7 \times 7$ and $17 \times 17$ grid boxes (second and outermost squares, respectively), and (d) the area means over all land grid boxes in the map domain. CTRL, SCEN and $\Delta$ denote the control run 10-year mean, the scenario run 10 -year mean and the relative change $(100 \% \times(\mathrm{SCEN} / \mathrm{CTRL}-1))$, respectively. $t$ is the $t$-statistics from eq. (A1).

Table 2. Annual control run area means (CTRL; for the whole land area) and simulated changes ( $\triangle$; for latitudes south (S55) and north (N55) of $55^{\circ} \mathrm{N}$ and for the whole land area) in some parameters

\begin{tabular}{|c|c|c|c|c|c|c|c|c|}
\hline & \multicolumn{2}{|c|}{ CTRL, All } & \multicolumn{2}{|c|}{$\Delta \mathrm{S} 55(\%)$} & \multicolumn{2}{|c|}{$\Delta \mathrm{N} 55(\%)$} & \multicolumn{2}{|c|}{$\Delta$ All $(\%)$} \\
\hline & $\mathrm{RH}$ & $\mathrm{RE}$ & RH & RE & $\mathrm{RH}$ & $\mathrm{RE}$ & $\mathrm{RH}$ & $\mathrm{RE}$ \\
\hline 1. $P_{\text {mean }}$ & 2.3 & $2.2 \mathrm{~mm} \mathrm{day}^{-1}$ & (5.4) & $(-5.7)$ & 17.1 & 15.8 & 10.5 & $(4.3)$ \\
\hline 2. $P_{\max }$ & 33.5 & $33.0 \mathrm{~mm}$ day $^{-1}$ & 12.1 & 15.8 & 18.6 & 16.2 & 14.6 & 16.0 \\
\hline 3. $P_{\max 6}$ & 18.3 & $19.7 \mathrm{~mm}(6 \mathrm{~h})^{-1}$ & 16.7 & 20.5 & 24.8 & 20.4 & 19.8 & 20.5 \\
\hline 4. $P_{\max 6}$, stratiform & 17.2 & $18.6 \mathrm{~mm}(6 \mathrm{~h})^{-1}$ & 16.4 & 19.8 & 23.6 & 19.8 & 19.2 & 19.8 \\
\hline 5. $P_{\max 6}$, convective & 10.0 & $10.6 \mathrm{~mm}(6 \mathrm{~h})^{-1}$ & 17.5 & 15.2 & 27.9 & 21.1 & 21.3 & 17.6 \\
\hline 6. $P_{\max }, 310 \mathrm{~km}$ & 22.2 & $22.1 \mathrm{~mm} \mathrm{day}^{-1}$ & 13.3 & 14.1 & 18.0 & 14.9 & 15.2 & 14.5 \\
\hline 7. $P_{\max 6}, 310 \mathrm{~km}$ & 9.2 & $10.3 \mathrm{~mm}(6 \mathrm{~h})^{-1}$ & 18.3 & 14.9 & 23.5 & 18.3 & 20.5 & 16.4 \\
\hline 8. $\quad N_{\text {wet }}(>1 \mathrm{~mm})$ & 154 & 144 days & $(-1.7)$ & -12.5 & 5.6 & (4.7) & (1.8) & $(-4.0)$ \\
\hline 9. $P_{\text {wet }}$ & 5.0 & $5.0 \mathrm{~mm} \mathrm{day}^{-1}$ & 8.1 & 8.3 & 13.1 & 12.8 & 9.9 & 9.9 \\
\hline 10. $\quad P_{\max }$, abs $(10 \mathrm{yr})$ & 56.3 & $56.0 \mathrm{~mm} \mathrm{day}^{-1}$ & 11.0 & 19.7 & 20.6 & 12.7 & 14.6 & 16.8 \\
\hline 11. $P_{\max 6}$, abs $(10 \mathrm{yr})$ & 32.8 & $35.6 \mathrm{~mm}(6 \mathrm{~h})^{-1}$ & 17.1 & 24.5 & 26.8 & 18.2 & 20.6 & 22.0 \\
\hline
\end{tabular}

All the changes in the last six columns are given in per cent of the control run area mean. Most of them are statistically significant at the $95 \%$ level according to the two-sided $t$-test (eq. (A1); applied on rows 1-9) or the pool permutation procedure of Preisendorfer and Barnett (1983) (rows 10-11); those that are not are given in parentheses.

wet days. By contrast, $P_{\text {wet }}$ and $P_{\max }$ increase in all seasons in both sub-regions in both $\mathrm{RH}$ and RE. The increase in $P_{\max }$ exceeds that in $P_{\text {wet }}$ with two exceptions in S55 ( RE in JJA and RH in SON). $P_{\max 6}$ increases more than either of $P_{\text {wet }}$ and $P_{\max }$ in all the cases considered (not shown).

The differences between RH and RE in the seasonal and annual area means of $P_{\text {wet }}$ and $P_{\max }$ change are, according to the modified $t$-test described in the end of Appendix A, all statistically insignificant (at the $95 \%$ level). The same is true for $P_{\text {mean }}$ with the exception of JJA, when the change in mean precipitation in both $\mathrm{N} 55$ and $\mathrm{S} 55$ is significantly more positive in $\mathrm{RH}$ than in

Tellus 53A (2001), 5 
a) Land north of $55^{\circ} \mathrm{N}$

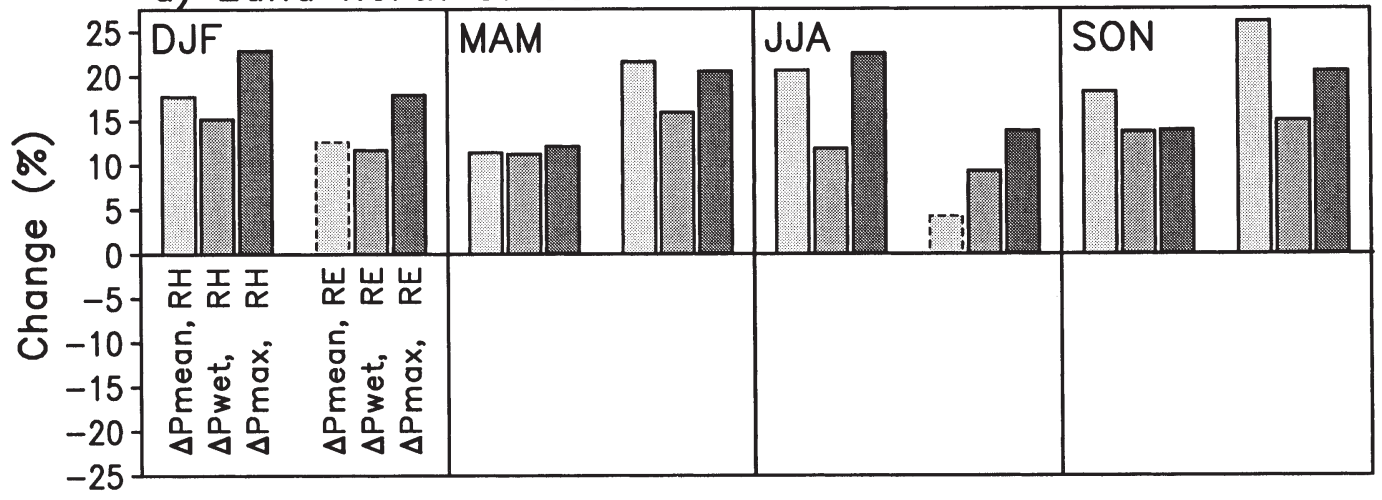

b) Land south of $55^{\circ} \mathrm{N}$

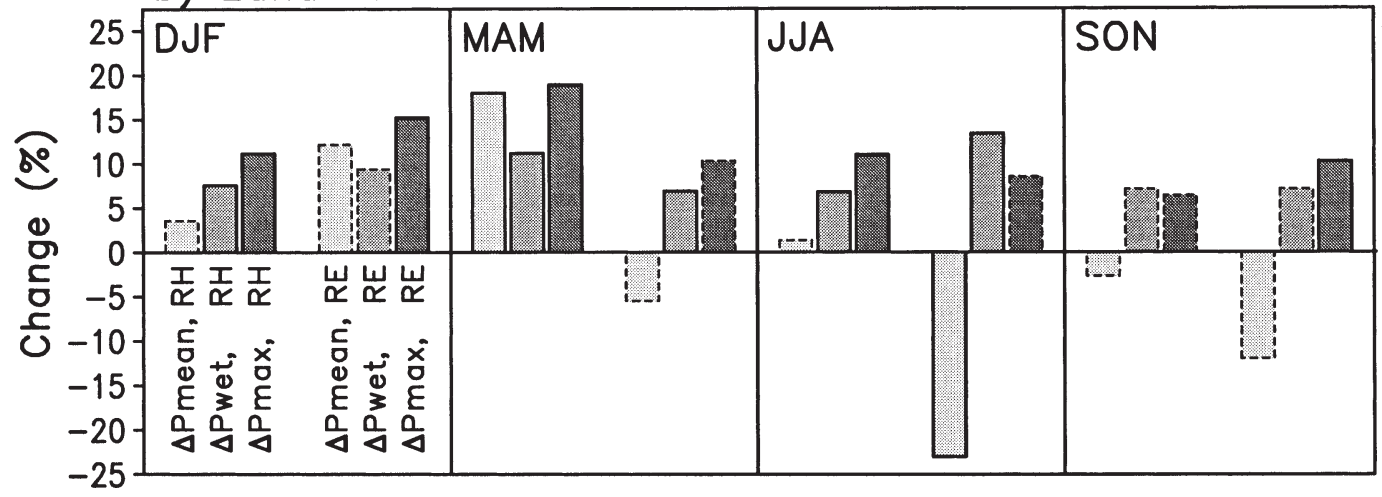

Fig. 5. Area mean seasonal changes in $P_{\text {mean }}$ (light bars), $P_{\text {wet }}$ (medium-dark bars) and $P_{\max }$ (dark bars) in the RH (first three bars in each box) and RE (last three bars) experiments. Solid (dashed) bar outline indicates that the changes are (are not) significant at the $95 \%$ level. (a) Land north of $55^{\circ} \mathrm{N}$; (b) land south of $55^{\circ} \mathrm{N}$.

RE. This difference is at least partly related to contrasting changes in the summertime atmospheric circulation. The scenario minus control run differences in JJA sea level pressure and lower tropospheric geopotential heights in $\mathrm{RH}$ feature a low pressure cell over Scandinavia, whereas the pattern in RE is dominated by a high centred over the North Sea (not shown). As a result, the changes in atmospheric moisture convergence are more positive in $\mathrm{RH}$ (corresponding to about $11 \%$ of the control run area mean precipitation in N55 and $-6 \%$ in S55) than in RE $(-2 \%$ in N55 and $-19 \%$ in S55). The decrease in JJA precipitation in RE in S55 appears to be exacerbated by a decrease in evaporation (corresponding to $4 \%$ of the control run precipitation, in contrast with a $7 \%$ increase in $\mathrm{RH}$ ) associated with reduced soil moisture.

\subsection{Factors affecting the extremes of stratiform precipitation}

Simulated greenhouse gas-induced increases in heavy precipitation have frequently been linked to the rapid increase in atmospheric moistureholding capacity with increasing temperature (e.g. Gordon et al., 1992; Frei et al., 1998). Precipitation is, however, proportional to the rate at which moisture is removed from the atmosphere, not to the moisture content as such. Some of the factors that are relevant for understanding the RCAsimulated changes in the extremes of (in this model, dominant) stratiform precipitation are discussed below. Related annual land area mean statistics for a lower $(850 \mathrm{hPa})$ and a midtropospheric pressure level $(500 \mathrm{hPa})$ are given in Table 3. 
Table 3. Control run land area means and simulated area mean changes in some parameters at 850 and $500 \mathrm{hPa}$

\begin{tabular}{|c|c|c|c|c|c|c|c|c|}
\hline & \multicolumn{2}{|c|}{$\begin{array}{l}\text { CTRL, } \\
850 \mathrm{hPa}\end{array}$} & \multicolumn{2}{|r|}{$\begin{array}{c}\text { CTRL, } \\
500 \mathrm{hPa}\end{array}$} & \multicolumn{2}{|c|}{$\begin{array}{l}\text { Change, } \\
850 \mathrm{hPa}\end{array}$} & \multicolumn{2}{|c|}{$\begin{array}{l}\text { Change, } \\
500 \mathrm{hPa}\end{array}$} \\
\hline & $\mathrm{RH}$ & RE & $\mathrm{RH}$ & RE & $\mathrm{RH}$ & RE & $\mathrm{RH}$ & RE \\
\hline 1. $T$ & 272.3 & 274.3 & 251.2 & $254.5 \mathrm{~K}$ & $3.2 \mathrm{~K}$ & $3.7 \mathrm{~K}$ & $3.8 \mathrm{~K}$ & $4.2 \mathrm{~K}$ \\
\hline 2. $R H$ & 0.759 & 0.725 & 0.601 & $0.578[1]$ & -0.014 & -0.017 & -0.008 & -0.020 \\
\hline 3. $q$ & 4.4 & 5.0 & 0.8 & $1.0 \mathrm{~g} \mathrm{~kg}^{-1}$ & $21.9 \%$ & $25.9 \%$ & $42.9 \%$ & $44.5 \%$ \\
\hline 4. $(-\omega)_{\max }$ & 1.5 & 1.5 & 2.3 & $2.3 \mathrm{~Pa} \mathrm{~s}^{-1}$ & $2.1 \%$ & $(1.6 \%)$ & $11.1 \%$ & $7.5 \%$ \\
\hline 5. $(-\omega q)_{\max }$ & 10.5 & 12.1 & 3.4 & $4.3 \times 10^{-3} \mathrm{~Pa} \mathrm{~s}^{-1}$ & $24.4 \%$ & $27.2 \%$ & $56.7 \%$ & $59.3 \%$ \\
\hline 6. $C_{\max }$ & 2.3 & 2.4 & 2.7 & $3.2 \times 10^{-7} \mathrm{~s}^{-1}$ & $10.5 \%$ & $8.3 \%$ & $38.7 \%$ & $35.2 \%$ \\
\hline
\end{tabular}

$T$, temperature; $R H$, relative humidity, $q$, specific humidity; $(-\omega)_{\max }$, average yearly maximum pressure co-ordinate rising motion; $(-\omega q)_{\max }$, maximum upward moisture flux; $C_{\max }$, maximum pseudo-adiabatic condensation rate (see text). The changes in temperature and relative humidity are given in absolute units and the changes in the other parameters in per cent of the control run area mean. Changes that are not statistically significant at the $95 \%$ level are given in parentheses.

The land area annual mean warming in the two experiments is $3.2-3.7 \mathrm{~K}$ at $850 \mathrm{hPa}$ and $3.8-4.2 \mathrm{~K}$ at $500 \mathrm{hPa}$ (row 1 of Table 3 ). Consequently, the average specific humidity $q$ increases by $22-26 \%$ at $850 \mathrm{hPa}$ and by $43-45 \%$ at $500 \mathrm{hPa}$, despite a slight decrease in relative humidity (rows 2 and $3)$. The per cent increase in $q$ is larger in the middle than in the lower troposphere mainly because the saturation pressure is in relative terms more sensitive to temperature in cold conditions (see eq. (2) below). The average vertically integrated moisture content increases by $25 \%$ in $\mathrm{RH}$ and by $28 \%$ in RE.

Precipitation requires condensation induced by rising motion. A large enough decrease in the intensity of the strongest rising motions could therefore lead to weaker precipitation extremes in a warmer climate. However, this does not happen in the RCA simulations. The changes in the tenyear area means of the yearly maximum pressure co-ordinate rising motion $(-\omega)_{\max }$, diagnosed from instantaneous $\omega$-fields stored at six-hour intervals, are shown on row 4 of Table 3. At $500 \mathrm{hPa}$, in particular, the average $(-\omega)_{\max }$ is substantially larger in the scenario than in the control runs (by $11 \%$ in $\mathrm{RH}$ and $8 \%$ in RE), perhaps due to the stronger latent heat release allowed by the larger moisture content. Consistent with the increase in $(-\omega)_{\max }$, the yearly extremes of upward moisture flux $(-\omega q)_{\max }$ increase even more than the specific humidity at both 850 and $500 \mathrm{hPa}$ (row 5 of Table 3 ).
From the increase in the extremes of rising motion, one might expect $P_{\max }$ and $P_{\max 6}$ to increase more than the atmospheric moisture content, and not less, as is actually the case. The apparent discrepancy may be partly a question of timescale: the $\omega$-fields used in deriving $(-\omega)_{\max }$ are instantaneous snapshots of model output, rather than 6- or 24-hour averages. However, there is another factor at play. In pseudo-adiabatic ascent, which is a good approximation when latent heat release is much stronger than other sources of diabatic heating, the condensation rate increases less steeply with atmospheric temperature than the moisture content does. First, the latent heat release associated with condensation counteracts the cooling induced by rising motion, as indicated by the thermodynamic equation

$c_{p} \frac{\mathrm{d} T}{\mathrm{~d} t}=\frac{R T}{p} \omega-L \frac{\mathrm{d} q_{\mathrm{s}}}{\mathrm{d} t}$

(for the symbols in eqs.(1)-(4), see Table 4). Therefore, for the same rising motion, the larger condensation rate $-\mathrm{d} q_{\mathrm{s}} / \mathrm{d} t$ makes the cooling of saturated air slower at higher temperatures. Second, the Clausius-Clapeyron relationship

$\frac{1}{e_{\mathrm{s}}} \frac{\mathrm{d} e_{\mathrm{s}}}{\mathrm{d} T}=\frac{L}{R_{\mathrm{v}} T^{2}}$

indicates that the water vapour saturation pressure $e_{\mathrm{s}}$, which is related to the saturation specific

Tellus 53A (2001), 5 
Table 4. Symbols used in eqs. (1)-(4)

\begin{tabular}{ll}
\hline Symbol & \multicolumn{1}{c}{ Explanation } \\
\hline$c_{p}$ & Specific heat capacity of air at constant \\
& pressure (for dry air, 1004 $\left.\mathrm{Jg}^{-1} \mathrm{~K}^{-1}\right)$ \\
$e_{\mathrm{s}}$ & Saturation pressure of water vapour \\
$L$ & Latent heat of vaporisation \\
& $\left(2.5 \times 10^{6} \mathrm{~J} \mathrm{~kg}^{-1}\right)$ or sublimation \\
& $\left(2.834 \times 10^{6} \mathrm{~J} \mathrm{~kg}^{-1}\right)$ : the latter value is \\
& used at $T<273.15 \mathrm{~K}$ \\
$q_{\mathrm{s}}$ & Specific humidity of saturated air \\
$p$ & Pressure \\
$R$ & Gas constant of a mixture of dry air and \\
& water vapour (for dry air, $\left.287 \mathrm{~J} \mathrm{~kg}^{-1} \mathrm{~K}^{-1}\right)$ \\
$R_{\mathrm{v}}$ & Gas constant of water vapour \\
& $\left(461 \mathrm{~J} \mathrm{~kg} \mathrm{~K}^{-1}\right)$ \\
$t$ & Time \\
$T$ & Temperature \\
$\omega$ & Vertical motion in pressure co-ordinates \\
& (d $p / \mathrm{d} t)$
\end{tabular}

humidity $q_{\mathrm{s}}$ via

$q_{\mathrm{s}}=\frac{R}{R_{\mathrm{v}}} \frac{e_{\mathrm{s}}}{p}$

is in relative terms most sensitive to temperature in cold conditions. Thus, for the same amount of pseudo-adiabatic cooling, warmer air will lose a smaller fraction of its water vapour by condensation.

Equations (1)-(3) can be combined to derive the rate at which condensation occurs in a pseudoadiabatically rising saturated air parcel. When one neglects in eq. (3) the fact that the gas constant $R$ for a mixture of dry air and water vapour is a weak function of specific humidity (Rogers and Yau, 1989, p. 18), the result becomes

$$
C \equiv-\frac{\mathrm{d} q_{\mathrm{s}}}{\mathrm{d} t} \approx-\omega \frac{q_{\mathrm{s}}}{p} \frac{\frac{R L}{R_{\mathrm{v}} c_{p} T}-1}{\frac{L^{2} q_{\mathrm{s}}}{R_{\mathrm{v}} c_{p} T^{2}}+1}
$$

This quantity was evaluated from the six-hourly RCA output, and its average yearly maxima $\left(C_{\max }\right)$ were calculated for each grid box. In this calculation, only cases with a relative humidity of over $90 \%$ were considered (however, this has little impact on the results because strong ascent is generally accompanied with high humidity). The values in the last row of Table 3 were obtained by assuming condensation to ice $(L=$
$2.834 \times 10^{6} \mathrm{~J} \mathrm{~kg}^{-1}$ instead of $2.5 \times 10^{6} \mathrm{~J} \mathrm{~kg}^{-1}$ ) at temperatures below $273.15 \mathrm{~K}$ and by neglecting the slight humidity dependence of $c_{p}$ and $R$ (Rogers and Yau, 1989, p. 18). However, the calculation was repeated by using $L=2.5 \times 10^{6} \mathrm{~J} \mathrm{~kg}^{-1}$ at all temperatures and by including the mentioned humidity dependencies, and the results were found to be reasonably insensitive to the details of the methodology. The calculated maximum condensation rate increases in the land area mean by about $10 \%$ at $850 \mathrm{hPa}$ and by $35-40 \%$ at $500 \mathrm{hPa}$. These increases are smaller than the increases in specific humidity and, in particular, the maximum upward moisture flux at the same levels.

By integrating $C$ vertically, one can estimate the rate of pseudo-adiabatic condensation in the whole atmospheric column. This calculation includes some numerical uncertainty associated with the coarse vertical resolution $(150-200 \mathrm{hPa})$ of the RCA output, but it suggests that the yearly maxima of vertically integrated condensation rate in the control runs have an average magnitude of 5-6 $\mathrm{mm}$ per hour and that the maxima in the scenario runs are about $25 \%$ larger. Both the control run values and the relative change are larger than the corresponding results for $P_{\max 6}$ in Section 4.2, but recalling that eq. (4) yields instantaneous rather than temporally averaged condensation rates, the differences are not implausible. Nonetheless, it is also important to note that eq. (4) represents a gross simplification of the parameterisation of stratiform precipitation in RCA. For example, condensed water vapour in the model does not fall down immediately but is rather first converted to cloud water that may be advected to neighbouring grid boxes.

\subsection{Wet-day frequency and atmospheric circulation}

The results in Section 4.2 indicate that the larger contrast between $\Delta P_{\max }$ and $\Delta P_{\text {mean }}$ in the southern than in the northern part of the RCA domain can be mainly explained by different changes in wetday frequency $\left(N_{\text {wet }}\right)$. One factor that likely affects the $N_{\text {wet }}$ changes is changes in atmospheric circulation. The $\mathrm{RH}$ and $\mathrm{RE}$ experiments both show greater annually averaged increases in the $850 \mathrm{hPa}$ height $Z 850$ in the southern than in the northern part of the domain (Fig. 6). This pattern of change suggests a northward shift in cyclone activity (which is supported by changes in band-pass 

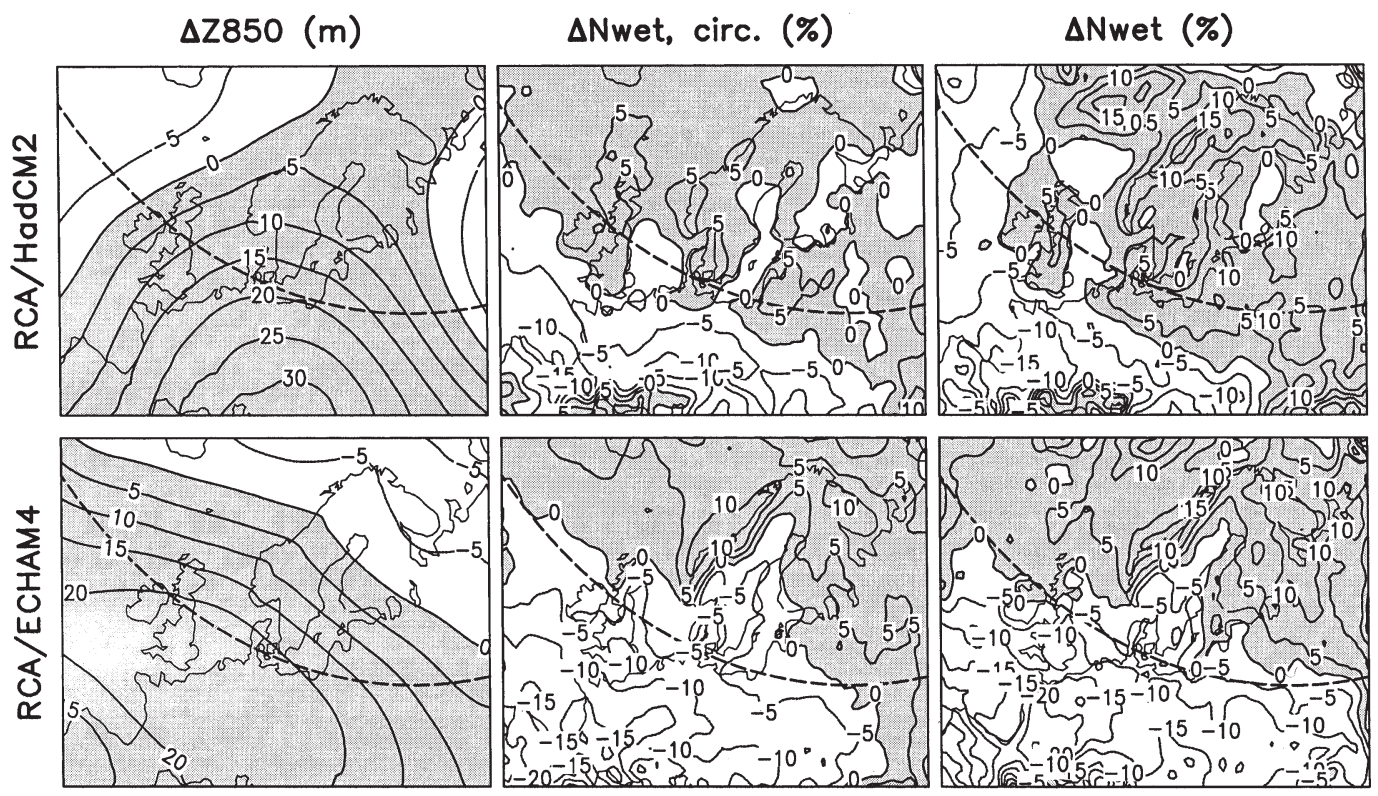

Fig. 6. Changes in the annual mean of $Z 850$ (left, metres), the changes in the number of wet days inferred with the regression model (5) (middle, \% of control run mean), and the actual simulated changes in the number of wet days (right). Positive values are shaded.

filtered height variability) and increased westerly flow from the Atlantic Ocean to northern Europe. Further south, $\Delta Z 850$ indicates a shift towards more anti-cyclonic conditions, in particular in RE where $\triangle Z 850$ is a maximum over western and central Europe. The annual Z850 changes in both $\mathrm{RH}$ and $\mathrm{RE}$ are reasonably large compared with internal variability (the threshold for 95\% significance is about $10 \mathrm{~m}$ ), but the differences between the two experiments are much harder to distinguish from noise. In both $\mathrm{RH}$ and $\mathrm{RE}$, the increased north-south gradient in $Z 850$ is particularly pronounced in autumn.

To estimate how such circulation changes might contribute to the changes in the number of wet days, a regression model was applied:

$$
\begin{aligned}
\Delta N_{\text {wet,circ }}= & A_{1} \Delta Z 850^{\prime \prime}+A_{2} \frac{\partial}{\partial \lambda} \Delta Z 850 \\
& +A_{3} \frac{\partial}{\partial \varphi} \Delta Z 850
\end{aligned}
$$

where $\Delta$ indicates a difference between the scenario and control run means and $\lambda$ and $\varphi$ are the model longitude and latitude, respectively. $Z 850^{\prime \prime}$ is the difference between the local $Z 850$ and its area mean over the whole model domain (see below). The frequency of precipitation days is expected to be related to both how cyclonic or anti-cyclonic the lower tropospheric flow is (precipitation tends to be more probable in cyclonic conditions) and the wind vector, which affects moisture and temperature advection and orographic vertical motions. $\Delta Z 850^{\prime \prime}$ is (the gradients of $\Delta Z 850$ are) used as an indicator of the former (latter) aspect of the circulation change.

The coefficients $A_{1}-A_{3}$ were derived separately for each grid box and each calendar month, using interannual variability in both the control and the scenario runs. First, monthly anomalies of $N_{\text {wet }}$ and the three predictors were calculated with respect to the corresponding control and scenario run 10 -year monthly means. Then, a least-square linear regression was made using the 20 sets of control and scenario run anomalies simultaneously. In systematic cross-verification (that is, when each of the 20 anomalies was predicted, in turn, by a regression based on the remaining 19 anomalies), this model explained $43 \%(46 \%)$ of the inter-annual variance of local monthly $N_{\text {wet }}$ anomalies in RH (RE). The corresponding 
fractions of explained variance for the best twopredictor $\left(Z^{\prime \prime}\right.$ and $\left.\partial Z^{\prime \prime} / \partial \varphi\right)$ and one-predictor $\left(Z^{\prime \prime}\right)$ models were $37 \%(40 \%)$ and $25 \% \quad(27 \%)$, respectively.

The changes in the annual wet-day frequency obtained by applying eq. (5) to the monthly 10 -year mean scenario minus control Z850 differences are shown in the mid-column of Fig. 6. The large-scale pattern of the actual changes (right column), with increases in the northern and decreases in the southern part of the domain, is qualitatively well reproduced, and the same also applies to some of the finer-scale details. The area mean $N_{\text {wet }}$ changes from the regression in N55 and $\mathrm{S} 55$ are $1.7 \%$ and $-3.3 \%$ for $\mathrm{RH}$, and $3.1 \%$ and $-8.4 \%$ for RE, respectively. Comparison with the actual values (Table 2, row 8 ) suggests that a substantial part of the contrasts between the two sub-regions, and between $\mathrm{RH}$ and $\mathrm{RE}$ in S55, are related to circulation changes, albeit with the caveat that the apparent similarity is no proof of a direct cause-effect relationship. However, the predicted increase in N55 and the predicted decrease in RE in S55 are somewhat smaller than those simulated. The latter difference is largest in the summer, which may be related to substantially reduced soil moisture in RE in S55.

The use of the $850 \mathrm{hPa}$ level in this exercise is somewhat arbitrary. However, other levels between 500 and $1000 \mathrm{hPa}$ give largely similar results when the area mean height change is neglected in the regression. When the area mean is retained, the inferred $\Delta N_{\text {wet }}$ grows increasingly more negative when higher levels are used. This is because the overall rise of pressure surfaces due to the warmer temperatures is erroneously "interpreted" by the regression model as an indication of more anti-cyclonic conditions.

\section{The signal-to-noise issue}

In the previous section, the statistical significance of the simulated $P_{\text {mean }}$ and $P_{\max }$ changes was estimated by using the $t$-test. However, regardless of whether the changes are significant or not, they are quantitatively affected by the noise in the short (10-year) simulations. In other words, the inferred scenario run minus control run climate changes are unlikely to be identical with the noise-free climate change signal specific to the model system used. How large is this "error" likely to be?

The noise-free climate change signal is defined here as the climate change that would be obtained by averaging over a large ensemble of experiments with the same greenhouse gas forcing, but with different (RCM and driving GCM) initial conditions (this signal may naturally be affected by model errors). The statistically expected magnitude of the noise-related error is characterised, in principle, by the variance between the individual ensemble members. In practice, we estimated this variance $(V 10)$ from the variability within the 10-year simulations, as described in Appendix B. A basic assumption in this method, which we believe to be quite well justified for precipitation, is that individual years are statistically independent from each other.

In Table 5 the standard error (square root of the land area mean of V10) associated with internal variability is given for the annual $P_{\max }$ and $P_{\text {mean }}$ changes on four slightly arbitrarily selected horizontal scales. In addition to the local, grid-box-scale changes, area mean changes on the $310 \mathrm{~km}$ and $750 \mathrm{~km}$ scales and over the whole land area are considered. The $310 \mathrm{~km}$ and $750 \mathrm{~km}$ scale changes are defined separately for each grid box, using means over the surrounding $7 \times 7$ or $17 \times 17$ grid boxes, before averaging the associated $V 10$ over the whole land area. As above, all changes and their standard errors are measured in relative terms ( $\%$ of control run mean).

The results for RH and RE are similar. Gridbox-scale values of $\Delta P_{\max }$ have a standard error of about $20 \%$, while the standard error for local $\Delta P_{\text {mean }}$ is only about $8 \%$. However, the inter-

Table 5. Standard error (\%) due to internal variability for simulated changes in $P_{\text {mean }}$ and $P_{\max }$ on different horizontal scales $(310 \mathrm{~km}=$ mean over $7 \times 7$ grid boxes; $750 \mathrm{~km}=$ mean over $17 \times 17$ grid boxes)

\begin{tabular}{lrrrrr}
\hline & \multicolumn{2}{c}{$\mathrm{RH}$} & & \multicolumn{2}{c}{$\mathrm{RE}$} \\
\cline { 2 - 3 } \cline { 5 - 6 } & $P_{\max }$ & $P_{\text {mean }}$ & & $P_{\text {max }}$ & $P_{\text {mean }}$ \\
\hline Grid box & 19.2 & 8.0 & & 20.0 & 8.4 \\
$310 \mathrm{~km}$ & 9.5 & 6.7 & & 9.6 & 7.3 \\
$750 \mathrm{~km}$ & 5.9 & 5.5 & & 5.7 & 6.2 \\
Land mean & 2.5 & 1.7 & & 2.1 & 3.5 \\
\hline
\end{tabular}


annual variations of $P_{\max }$ have a smaller horizontal scale than those of $P_{\text {mean }}$, and horizontal averaging therefore reduces the standard error of $\Delta P_{\max }$ more rapidly than the error of $\Delta P_{\text {mean }}$. On the two largest scales $(750 \mathrm{~km}$ and land area mean), the error estimates for the two parameters are, perhaps surprisingly, quite similar to each other.

Using the V10 estimates and the actual simulated climate changes, it is of interest to complement the $t$-test results discussed in Section 4 with a statistic that we call the change-to-noise ratio $(C N)$. This is calculated as

$C N=\widetilde{(\Delta P)^{2}} / V 10$

where the wavy lines denote area means over the whole land area and $\Delta P$ refers to either of $\Delta P_{\text {mean }}$ or $\Delta P_{\max } . C N$ can also been evaluated (in an analogous way) for the $\Delta P_{\max }-\Delta P_{\text {mean }}$ difference and for the differences in $\Delta P_{\text {mean }}$ and $\Delta P_{\max }$ between RH and RE.

At the limit of large samples (i.e., infinite number of independent grid boxes), the internal variability and the real climate change signal can be assumed to be uncorrelated with each other, and are therefore additive in terms of the squared amplitude. In this case, $C N=2$ indicates that the signal and the noise have equal magnitude. This remains a useful first guideline of interpretation even when dealing with the more limited samples studied here. However, it should also be stressed that the interpretation of $C N$ becomes increasingly uncertain with decreasing sample size. Thus, although $C N$ is evaluated in Table 6 for horizontally averaged ( $310 \mathrm{~km}$ scale to land area mean) as well as for local climate changes, the results on the largest scales are, at best, suggestive. The main indications from this table are the following:

(1) Grid-box-scale changes in $P_{\max }$ have a relatively low $C N$ ratio (more than a half of the squared amplitude is attributed to internal varia- bility). Local $P_{\text {mean }}$ changes are somewhat less severely contaminated by internal variability.

(2) The $C N$ ratios increase with increasing horizontal scale, excluding the low ratio (1.5) for the area mean $\Delta P_{\text {mean }}$ in $\mathrm{RE}$ that reflects a near cancellation between opposing changes in the northern and southern parts of the domain. Even when this feature is disregarded, the difference in the scale dependence of noise makes the increase in $C N$ with increasing scale steeper for $\Delta P_{\max }$ than for $\Delta P_{\text {mean }}$

(3) The $\Delta P_{\max }-\Delta P_{\text {mean }}$ differences have a higher $C N$ ratio in $\mathrm{RE}$ than in $\mathrm{RH}$.

(4) The previous result is difficult to interpret, because a majority of the $\mathrm{RH}-\mathrm{RE}$ differences in both $\Delta P_{\text {max }}$ and $\Delta P_{\text {mean }}$ seem to arise from internal variability at least up to the $750 \mathrm{~km}$ scale.

The last point also suggests that, if longer RCA experiments had been made using boundary data from the same two GCMs, the differences between RH and RE might have been substantially smaller. Of course, the only rigorous way to verify this suggestion would be to actually conduct such longer experiments.

Finally, we consider an issue that is of importance in climate change impact research. The results in Table 5 indicate that, disregarding sources of uncertainty other than internal variability, model results give much better estimates of large-scale area means of $\Delta P_{\max }$ than of the local changes. However, in many impact studies, it is the local climate change that matters. Should this be estimated directly from the simulated grid box values, despite the strong noise, or should the grid box values be averaged over a larger area? The latter strategy reduces the noise, but, on the other hand, the local climate change signal may differ from the larger-scale signal. Putting this in quantitative terms, the statistically expected squared error $E^{2}$ for estimating the local noise-free climate

Table 6. The change-to-noise ratio (see text) for some parameters on different scales

\begin{tabular}{|c|c|c|c|c|c|c|c|c|}
\hline & \multicolumn{3}{|c|}{$\mathrm{RH}$} & \multicolumn{3}{|c|}{$\mathrm{RE}$} & \multicolumn{2}{|c|}{$\mathrm{RH}-\mathrm{RE}$} \\
\hline & $\Delta P_{\max }$ & $\Delta P_{\text {mean }}$ & $\Delta P_{\max }-\Delta P_{\text {mean }}$ & $\Delta P_{\max }$ & $\Delta P_{\text {mean }}$ & $\Delta P_{\max }-\Delta P_{\text {mean }}$ & $\Delta P_{\max }$ & $\Delta P_{\text {mean }}$ \\
\hline Grid box & 1.8 & 3.9 & 1.1 & 1.8 & 3.3 & 1.9 & 1.1 & 1.7 \\
\hline $310 \mathrm{~km}$ & 4.1 & 4.5 & 1.4 & 4.0 & 3.9 & 4.3 & 1.3 & 1.7 \\
\hline $750 \mathrm{~km}$ & 8.4 & 5.8 & 1.6 & 9.1 & 4.7 & 7.5 & 1.3 & 1.5 \\
\hline Land mean & 34.8 & 38.4 & 2.3 & 58.8 & 1.5 & 13.0 & 0.2 & 2.6 \\
\hline
\end{tabular}

Tellus 53A (2001), 5 
change signal from a simulated large-scale mean climate change is

$E^{2}=V 10_{\mathrm{LS}}+\left(S_{\mathrm{LOC}}-S_{\mathrm{LS}}\right)^{2}$

where $V 10_{\mathrm{LS}}$ is the variance associated with the internal variability of the large-scale mean climate change ("noise error") and $\left(S_{\mathrm{LOC}}-S_{\mathrm{LS}}\right)^{2}$ is the squared difference between the local climate change signal and the larger-scale mean signal ("signal error").

An obvious problem with eq. (7) is that the signals $S_{\mathrm{LOC}}$ and $S_{\mathrm{LS}}$ are both unknown. Their squared difference can only be estimated as a residual, by subtracting from the squared difference between the simulated local $\left(\Delta P_{\text {LOC }}\right)$ and larger-scale $\left(\Delta P_{\mathrm{LS}}\right)$ climate changes the squared difference on average expected from internal variability, that is, the variance $V 10_{\mathrm{LOC}-\mathrm{LS}}$ characterising the noise in $\Delta P_{\mathrm{LOC}}-\Delta P_{\mathrm{LS}}$

$\left(S_{\mathrm{LOC}}-S_{\mathrm{LS}}\right)^{2} \approx\left(\Delta P_{\mathrm{LOC}}-\Delta P_{\mathrm{LS}}\right)^{2}-V 10_{\mathrm{LOC}-\mathrm{LS}}$

The words "on average" in the previous sentence are important. In any single grid box, the squared difference between $\Delta P_{\mathrm{LOC}}$ and $\Delta P_{\mathrm{LS}}$ may be much larger or smaller than its statistically expected value. In the latter case, the inferred $\left(S_{\mathrm{LOC}}-S_{\mathrm{LS}}\right)^{2}$ may be substantially negative. Even when averaged over the whole land area, there is, in several of the cases studied, a strong cancellation between the two right-hand-side terms in eq. (8). For example, when estimating the local $\Delta P_{\max }$ in RE from $\Delta P_{\max }$ on the $750 \mathrm{~km}$ scale, the area mean of $\left(\Delta P_{\mathrm{LOC}}-\Delta P_{\mathrm{LS}}\right)^{2}$ is $382 \%{ }^{2}$ and that of $V 10_{\mathrm{LOC}-\mathrm{LS}}$ $352 \%{ }^{2}$. The values for RH are $321 \%{ }^{2}$ and $322 \%{ }^{2}$, respectively, which gives a physically unrealistic difference of $-1 \%{ }^{2}$. Obviously, $\left(S_{\mathrm{LOC}}-S_{\mathrm{LS}}\right)^{2}$ cannot be estimated very accurately. However, the strong cancellation itself is important, since it implies that a large majority of the small-scale variations in $\Delta P_{\max }$ are indeed likely to be noise.

The calculated total root-mean-square (r.m.s.) errors (square root of the area mean of $E^{2}$ ) for estimating the local $\Delta P_{\max }$ signal from the simulated $\Delta P_{\max }$ on different scales are given in the first data row of Table 7. Also given are, in parentheses, the r.m.s. values of the signal error (8) alone; as discussed above, these are quite uncertain. In any case, the results for the total r.m.s. error in RH and RE are qualitatively similar. The signal difference is far too small to outweigh the advantage of reduced noise when the local $\Delta P_{\max }$ is replaced with larger-scale means. For RH, the r.m.s. error is estimated to be smallest when using the $750 \mathrm{~km}$ scale means (5.9\%), for RE when using the mean for the whole land area $(7.4 \%)$. Thus, in both cases, substantially better estimates of the local $\Delta P_{\max }$ signal appear to be obtainable by a strong horizontal averaging of the results.

Should horizontal averaging also be used when estimating the change in the mean rather than the maximum precipitation? The results in this case are less clear-cut (second row of Table 7). Nevertheless, a smoothing up to the $750 \mathrm{~km}$ scale does not appear to worsen the $\Delta P_{\text {mean }}$ estimates in either RH or RE.

Experiments longer than those discussed here would be less strongly affected by internal variability, which would make the benefits of horizontal averaging smaller. As an example, the last row in Table 7 shows the hypothetical error estimates for inferring the $\Delta P_{\max }$ signal from 40-year rather than 10 -year simulations. The noise variance is assumed to scale inversely with the averaging period, whereas the signal error is independent of the period. Thus, the r.m.s. error for using the local value of $\Delta P_{\max }$ as such is halved, whereas in the cases in which signal error is also involved, the relative decrease in r.m.s. error is smaller. Nevertheless, some averaging of the raw model results (at least up to the $310 \mathrm{~km}$ scale) would still appear to be useful.

\section{Summary}

Two regional $44 \mathrm{~km}$ resolution climate change experiments for northern and central Europe have been analysed focussing mainly on the changes in annual mean precipitation $\left(P_{\text {mean }}\right)$ and the yearly maximum one-day precipitation $\left(P_{\max }\right)$. Each experiment consists of a 10-year control run and a 10-year scenario run representing a possible future with higher greenhouse gas concentrations and, in both the two driving GCMs, a $2.6 \mathrm{~K}$ higher global mean temperature. The main findings are listed below.

(1) The control run $P_{\text {mean }}$ distributions show a reasonable pattern similarity with the observed distribution, but the simulated $P_{\text {mean }}$ exceeds the observed values in much of the model area. At 
Table 7. Statistically estimated root-mean-square error (\%) when approximating the local noise-free climate change signal in $P_{\max }$ or $P_{\text {mean }}$ with the simulated change in the same parameter on different horizontal scales (the contribution of the signal error is given in parentheses)

\begin{tabular}{|c|c|c|c|c|c|c|c|c|}
\hline & \multicolumn{4}{|c|}{ RH } & \multicolumn{4}{|c|}{$\mathrm{RE}$} \\
\hline & Grid box & $310 \mathrm{~km}$ & $750 \mathrm{~km}$ & Land mean & Grid box & $310 \mathrm{~km}$ & $750 \mathrm{~km}$ & Land mean \\
\hline$\Delta P_{\max }$ & $\begin{array}{l}19.2 \\
(0.0)\end{array}$ & $\begin{array}{l}9.5 \\
(0.0)\end{array}$ & $\begin{array}{c}5.9 \\
(0.0)\end{array}$ & $\begin{array}{c}6.3 \\
(5.8)\end{array}$ & $\begin{array}{l}20.0 \\
(0.0)\end{array}$ & $\begin{array}{l}10.2 \\
(3.5)\end{array}$ & $\begin{array}{c}7.9 \\
(5.5)\end{array}$ & $\begin{array}{c}7.4 \\
(7.1)\end{array}$ \\
\hline$\Delta P_{\text {mean }}$ & $\begin{array}{c}8.0 \\
(0.0)\end{array}$ & $\begin{array}{c}7.8 \\
(4.0)\end{array}$ & $\begin{array}{c}8.0 \\
(5.8)\end{array}$ & $\begin{array}{c}7.6 \\
(7.4)\end{array}$ & $\begin{array}{c}8.4 \\
(0.0)\end{array}$ & $\begin{array}{c}7.7 \\
(2.4)\end{array}$ & $\begin{array}{c}7.0 \\
(3.2)\end{array}$ & $\begin{array}{c}13.2 \\
(12.7)\end{array}$ \\
\hline $\begin{array}{l}\Delta P_{\max }, \\
40 \mathrm{yr} \text { of data }\end{array}$ & $\begin{array}{c}9.6 \\
(0.0)\end{array}$ & $\begin{array}{c}4.7 \\
(0.0)\end{array}$ & $\begin{array}{c}2.9 \\
(0.0)\end{array}$ & $\begin{array}{c}5.9 \\
(5.8)\end{array}$ & $\begin{array}{l}10.0 \\
(0.0)\end{array}$ & $\begin{array}{c}5.9 \\
(3.5)\end{array}$ & $\begin{array}{c}6.2 \\
(5.5)\end{array}$ & $\begin{array}{c}7.2 \\
(7.1)\end{array}$ \\
\hline
\end{tabular}

the 12 Swedish stations studied, the simulated $P_{\max }$ has quite a realistic magnitude.

(2) In the scenario runs, $P_{\text {mean }}$ increases in northern Europe but decreases further south over the continent, especially in one of the two experiments. $P_{\max }$ increases on the average by $15 \%$ and the increase even extends to most of the areas where $P_{\text {mean }}$ decreases.

(3) The decrease in $P_{\text {mean }}$ in the southern part of the domain can be explained by a decrease in the number of wet days with at least $1 \mathrm{~mm}$ of precipitation. Further north, the wet-day frequency generally increases in the experiments. This dipole pattern is at least partly associated with changes in atmospheric circulation.

(4) The average precipitation for all wet days increases in both central and northern Europe, but generally somewhat less than $P_{\max }$.

(5) The timescale of heavy precipitation appears to decrease. The average increase in the yearly maximum six-hour precipitation, about $20 \%$ in both experiments, exceeds that in the oneday $P_{\max }$. Calculations of the pseudo-adiabatic condensation rate hint that the increase in maximum instantaneous precipitation rates might be even larger.

(6) The grid-box-scale changes in $P_{\max }$ are heavily affected by internal variability in the short simulations, much more so than the changes in $P_{\text {mean }}$. However, the error associated with this noise can be reduced substantially by a horizontal averaging of the results. The disadvantage that such averaging also smoothens out part of the real climate change signal is, in the case of the $P_{\max }$ changes, much smaller than the advantage of reduced noise.
(7) A large part of the differences in $P_{\text {mean }}$ and $P_{\max }$ changes between the two experiments may be explained by the brevity of the simulations.

Some of these results should be checked with other models (in particular, the decrease in the timescale of heavy precipitation) or by conducting longer simulations (the importance of internal variability). However, our basic finding of stronger precipitation extremes in a warmer climate is by no means new. Thus, to the extent that this can be addressed by comparing different model simulations, a general intensification of heavy precipitation events may be regarded as being a very probable consequence of an enhanced greenhouse effect.

\section{Acknowledgements}

The SWECLIM programme and the Rossby Centre are funded by MISTRA and by SMHI. The HadCM2 data used to drive RCA were provided by the Hadley Centre, and the ECHAM4 data by the Max Planck Institute for Meteorology and the German Climate Computing Centre. The latter data management benefited from co-operation with the Norwegian RegClim project. RCA has been run on the CRAY T3E at the Swedish National Supercomputing Centre (NSC). The Rossby Centre staff members are acknowledged for their efforts in developing the RCA model and conducting the experiments analysed here, and the two anonymous reviewers for their constructive comments that led to a substantial improvement of the original manuscript. 


\section{Appendix A}

\section{Testing statistical significance}

To test whether there is a statistically significant difference in mean between two samples of yearly data, such as the control run and observations or the scenario run and the control run, the $t$-statistic is used. If the two samples consist of $n_{X}$ and $n_{Y}$ values and have means $M_{X}$ and $M_{Y}$ and (" $n-1$ " form) variances $V_{X}$ and $V_{Y}$, then

$t=\frac{M_{Y}-M_{X}}{V_{X Y}^{1 / 2}}$

where

$V_{X Y}=\left(\frac{1}{n_{X}}+\frac{1}{n_{Y}}\right) \frac{\left(n_{X}-1\right) V_{X}+\left(n_{Y}-1\right) V_{Y}}{n_{X}+n_{Y}-2}$.

In the comparison between the RCA control and scenario runs $n_{X}=n_{Y}=10$, so that

$V_{X Y}=\frac{V_{X}+V_{Y}}{10}$

and the statistics have $n_{X}+n_{Y}-2=18$ degrees of freedom. The critical absolute $t$-value for twosided $95 \%$ significance in this case is 2.101 .

The test (A1) assumes that the data are not serially correlated, that they are normally distributed, and that the two samples come from populations with equal variance. Serial correlation is difficult to judge from short time series but we do not expect it to be a serious problem in the case of yearly $P_{\max }$ and $P_{\text {mean }}$ values. Deviations from normality might appear to be a bigger issue, at least for $P_{\max }$, but the $t$-test is relatively insensitive to these. We also applied, to many of the cases studied, a significance test based on the pool permutation procedure of Preisendorfer and Barnett (1983), which does not require normally distributed data. The resulting significance levels were almost identical with those obtained from eq. (A1). Possible differences in variance can be approximately accounted for as described by von Storch and Zwiers (1999, p. 113). Such a procedure was also tested and was found to yield only modest changes to the significance estimates based on eq. (A1), in particular when comparing the RCA scenario and control runs with equal sample size.

The test (A1) is used to judge whether the scenario minus control run climate change in a given parameter in a given experiment differs significantly from zero. Another important but more delicate question is whether or not two relative $(\%)$ climate changes are significantly different from each other (e.g. is $\Delta P_{\max }$ in $\mathrm{RH}$ significantly different from $\Delta P_{\text {mean }}$ in $\mathrm{RH}$, or from $\Delta P_{\max }$ in RE). This is tested as described by Räisänen et al. (2001). Denoting the yearly control (scenario) run values in the two data sets compared as $X_{1}$ and $X_{2}\left(Y_{1}\right.$ and $\left.Y_{2}\right)$, the test (A1) is applied to the 10 -year means and variances of

$X_{\text {Diff }}=X_{1}-A X_{2}$

and

$Y_{\text {Diff }}=Y_{1}-A Y_{2}$

where the coefficient $A$ is calculated from the 10-year means of $X_{1}, X_{2}, Y_{1}$ and $Y_{2}$ as

$A=\frac{M_{X 1}+M_{Y 1}}{M_{X 2}+M_{Y 2}}$

This scaling ensures that $t=0$ when the relative $(\%)$ scenario minus control climate change is the same in both cases.

\section{Appendix B}

\section{Error associated with internal variability}

To estimate the magnitude of error that internal variability is likely to cause to the relative $P_{\text {mean }}$ and $P_{\max }$ changes in the 10 -year experiments, the experiments were first divided into two 5-year parts. Assuming that the individual years are statistically independent from each other, the ordering of the years does not matter and this division can be done in $(10 !) /(5 !)^{2}=252$ different ways. In each case, the relative scenario minus control climate change was calculated separately for these two 5-year samples. Denoting the two 5 -year estimates of climate change as $F 1$ and $F 2$, the estimate for the variance of 5-year climate changes becomes

$V 5=\frac{1}{2} \overline{(F 1-F 2)^{2}}$

where the over-line indicates averaging over all choices of the two 5-year periods. The variance of 10 -year climate changes is estimated as

$V 10=\frac{5}{10} V 5$, 
assuming that the variance is inversely proportional to the averaging period. This assumption is, in the absence of inter-annual auto-correlation, exactly true when the scenario minus control differences are measured in absolute units. To study how well it holds for the relative $(\%)$ differences used here, (B2) was replaced with the more general form

$V n=\frac{n}{10} V n$,

where $V n$ denotes the variance of $n$-year $(n \leqslant 5)$ climate changes estimated with the same principle as $V 5$. Taking the grid box scale changes in $P_{\max }$ in $\mathrm{RE}$ as a characteristic example, $n=3$ yielded a $2 \%$ higher estimate of the area mean of $V 10$ than $n=5$. For $n=2$ and $n=1$, the difference increased to $4 \%$ and $14 \%$, respectively. Extrapolating to the other direction, the $V 10$ estimates from (B2) may also be slightly too large but the error appears small.

It might be tempting to estimate $V 10$ simply as

$V 10 \approx V_{X Y}\left(\frac{100 \%}{M_{X}}\right)^{2}$

where $V_{X Y}$ is the variance used in the $t$-test (A3) and $M_{X}$ is the 10-year control run mean. This would, however, give biased results. As discussed by Räisänen et al. (2001), the sensitivity of a relative $(\%)$ scenario minus control run climate change to random variations in the control run mean depends on the relative change itself. For example, when $P_{\max }$ is $20 \%$ larger in the scenario than in the control run, a further $1 \%$ perturbation in the control run mean causes a $-1.2 \%$ rather than $-1 \%$ perturbation in the relative change.

The method described above can be generalised in an obvious way to estimating the variance in the difference between two climate changes (e.g. $\left.\Delta P_{\max }-\Delta P_{\text {mean }}\right)$.

\section{REFERENCES}

Christensen, O. B., Christensen, J. H., Machenhauer, B. and Botzet, M. 1998. Very high-resolution regional climate simulations over Scandinavia - present climate. J. Climate 11, 3204-3229.

Easterling, D. R., Evans, J. L., Groisman, P. Ya., Karl, T. R., Kunkel, K. E. and Ambenje, P. 2000. Observed variability and trends in extreme climate events: a brief review. Bull. Am. Meteorol. Soc. 81, 417-425.

Eerola, K., Salmond, D., Gustafsson, N., Garcia-Moya, J.-A., Lönnberg, P. and Järvenoja, S. 1997. A parallel version of the HIRLAM forecast model: Strategy and results. In Hoffmann, G.-R. and Kreitz, N. (eds): Proceedings of the seventh ECMWF Workshop on the use of parallel processors in meteorology. World Scientific Publishing, Singapore, 134-143.

Frei, C., Schär, C., Lüthi, D. and Davies, H. C. 1998. Heavy precipitation processes in a warmer climate. Geophys. Res. Lett. 25, 1431-1434.

Gordon, H. B., Whetton, P. H., Pittock, A. B., Fowler, A. M. and Haylock, M. R. 1992. Simulated changes in daily rainfall intensity due to the enhanced greenhouse effect: implications for extreme rainfall events. Clim. Dynam. 8, 83-102.

Gregory, J. M. and Mitchell, J. F. B. 1995. Simulation of daily variability of surface temperature and precipitation over Europe in the current and $2 \times \mathrm{CO}_{2}$ climates using the UKMO climate model. Q. J. R. Meteorol. Soc. 121, 1451-1476.

Hennessy, K. J., Gregory, J. M. and Mitchell, J. F. B. 1997. Changes in daily precipitation under enhanced greenhouse conditions. Clim. Dynam. 13, 667-680.
Hulme, M., Conway D., Jones, P. D., Jiang, T., Zhou, X., Barrow, E. M. and Turney, C. 1995. A 1961-90 Gridded Surface Climatology for Europe. Climatic Research Unit, University of East Anglia, Norwich, United Kingdom, 51 pp. + maps.

Johns, T. C., Carnell, R. E., Crossley, J. F., Gregory, J. M., Mitchell, J. F. B., Senior, C. A., Tett, S. F. B. and Wood, R. A. 1997. The second Hadley Centre coupled ocean-atmosphere GCM: model description, spinup and validation. Clim. Dynam. 13, 103-134.

Jones, R. G., Murphy, J. M., Noquer, M. and Keen, A. B. 1997. Simulation of climate change over Europe using a nested regional-climate model. II: Comparison of driving and regional model responses to a doubling of carbon dioxide. Q. J. R. Meteorol. Soc. 123, 265-292.

Källén, E. (ed) 1996. HIRLAM documentation manual. System 2.5. 178 pp. +55 pp. appendix. Available from SMHI, S-60176 Norrköping, Sweden.

Kuo, H. L. 1965. On the formation and intensification of tropical cyclone through latent heat release by cumulus convection. J. Atmos. Sci. 22, 40-63.

Kuo, H. L. 1974. Further studies of the parameterization of the influence of cumulus convection on large-scale flow. J. Atmos. Sci. 31, 1232-1240.

Ljungemyr, P., Gustafsson, N. and Omstedt, A. 1996. Parameterization of lake thermodynamics in a high resolution weather forecasting model. Tellus $\mathbf{4 8 A}$, 608-621.

Machenhauer, B., Windelband, M., Botzet, M., Christensen, J. H., Déqué, M., Jones, R. G., Ruti, P. M. and Visconti, G. 1998. Validation and analysis of regional

Tellus 53A (2001), 5 
present-day climate and climate change simulations over Europe. Max-Planck-Institut für Meteorologie, Report No. 275, Hamburg, 87 pp. + figures and tables

Meehl, G. A., Zwiers, F., Evans, J., Knutson, T., Mearns, L. and Whetton, P. 2000. Trends in extreme weather and climate events: issues related to modeling extremes in projections of future climate change. Bull. Am. Meteorol. Soc. 81, 427-436.

Mitchell, J. F. B. and Johns, T. C. 1997. On modification of global warming by sulphate aerosols. J. Climate 10, 245-267.

Noda, A. and Tokioka, T. 1989. The effect of doubling of $\mathrm{CO}_{2}$ concentration on convective and non-convective precipitation in a general circulation mode coupled with a simple mixed layer ocean model J. Meterol. Soc. Jpn. 67, 1057-1069.

Oberhuber, J. M. 1993. Simulation of the Atlantic circulation with a coupled sea ice-mixed layer-isopycnal general circulation model. Part I: Model description. J. Phys. Oceanogr. 22, 808-829.

Omstedt, A. 1999. Forecasting ice on lakes, estuaries and shelf seas. In: Ice physics in the natural and endangered environment (eds J. S. Wettlaufer, J. G. Dash and N. Untersteiner), NATO ASI Vol I 56, Springer-Verlag, Berlin, Heidelberg, pp. 185-208.

Omstedt, A. and Nyberg, L. 1996. Response of Baltic Sea ice to seasonal, interannual forcing and climate change. Tellus 48A, 644-662.

Parey, S. 1994. Simulations de trente ans $1 \times \mathrm{CO}_{2}$, $2 \times \mathrm{CO}_{2}, \quad 3 \times \mathrm{CO}_{2}$ avec le modele du LMD $(64 \times 50 \times 11)$ premiers resultats. EDF, Directions des Etudes et Reserches, HE-33/94/008, 103 pp. Available from Electricité de France, Groupe Météorologie et Climat, 6, Quai Watier, Boite Postale 49, F-78401 Chatou Cedex, France.

Preisendorfer, R. W. and Barnett, T. P. 1983. Numerical model reality intercomparison tests using small sample statistics. J. Atmos. Sci. 40, 1884-1896.

Räisänen, P., Rummukainen, M. and Räisänen, J. 2000. Modification of the HIRLAM radiation scheme for use in the Rossby Centre regional atmospheric climate model. Report No. 49, Department of Meteorology, University of Helsinki, Finland, 71 pp.

Räisänen, J., Rummukainen, M. and Ullerstig, A. 2001. Downscaling of greenhouse gas induced climate change in two GCMs with the Rossby Centre regional climate model for northern Europe. Tellus 53A, $168-192$.

Roeckner, E., Arpe, K., Bengtsson, L., Christoph, M. Claussen, M., Dümenil, L., Esch, M., Giorgetta, M., Schlese, U. and Schulzweida, U. 1996. The atmospheric general circulation model ECHAM-4: Model description and simulation of present-day climate. Max-Planck-Institut für Meteorologie, Report No. 218, Hamburg, Germany, 90 pp.

Roeckner, E., Bengtsson, L., Feichter, J., Lelieveld, J. and Rodhe, H. 1999. Transient climate change simulations with a coupled atmosphere-ocean GCM including the tropospheric sulfur cycle. J. Climate, 12, 3004-3032.

Rogers, R. R. and Yau, M. K. 1989. A short course in cloud physics, third edition. Pergamon Press, Oxford, 293 pp.

Rummukainen, M., Räisänen, J., Bringfelt, B., Ullerstig, A., Omstedt, A., Willén, U., Hansson, U. and Jones, C. 2001. A regional climate model for northern Europe model description and results from the downscaling of two GCM control simulations. Clim. Dynam. 17, 339-359.

Sundqvist, H. 1993. Inclusion of ice phase of hydrometeors in cloud parameterization for mesoscale and largescale models. Beitr. Phys. Atmos. 66, 137-147.

Sundqvist, H., Berge, E. and Kristjánsson, J. E. 1989.

Condensation and cloud parameterization studies with a mesoscale numerical weather prediction model. Mon. Wea. Rev. 117, 1641-1657.

von Storch, H. and Zwiers, F. W. 1999. Statistical analysis in climate research. Cambridge University Press, $484 \mathrm{pp}$

Whetton, P. H., Fowler, A. M., Haylock, M. R. and Pittock, A. B. 1993. Implications of climate change due to the enhanced greenhouse effect on floods and droughts in Australia. Clim. Change 25, 289-317.

Zwiers, F. W. and Kharin, V. V. 1998. Changes in the extremes of the climate simulated by the CCC GCM2 under $\mathrm{CO}_{2}$ doubling. J. Climate 11, 2200-2222. 